\title{
The Determinants of M-Health Adoption in Developing Countries: An Empirical Investigation
}

\author{
Ahmad Alaiad ${ }^{1}$ Mohammad Alsharo ${ }^{2}$ Yazan Alnsour ${ }^{3}$ \\ ${ }^{1}$ Department of Computer Information Systems, Jordan University of \\ Science and Technology, Irbid, Jordan \\ 2 Department of Information Systems, Al Albayt University, Mafraq, \\ Jordan \\ ${ }^{3}$ Accounting and Computer Information Systems Department, \\ Address for correspondence Ahmad Alaiad, PhD, Department of \\ Computer Information Systems, Jordan University of Science and \\ Technology, P.O. Box 3030, Irbid 22110, Jordan \\ (e-mail: Aiaiad@just.edu.jo).
} Monfort College of Business, University of Northern Colorado, Greeley, Colorado, United States

Appl Clin Inform 2019;10:820-840.

\section{Abstract}

Keywords

- M-Health

- technology acceptance

- UTAUT

- dual-factor model

- health belief model

- M-Health in developing countries
Background The potential benefit of mobile health (M-Health) in developing countries for improving the efficiency of health care service delivery, health care quality, and patient safety, as well as reducing cost, has been increasingly recognized and emphasized in the last few years.

Objective Limited research has investigated the facilitators and barriers for the adoption of M-Health in developing countries to secure successful implementation of the technology. To fill this knowledge gap, we propose an integrative model that explains the patient's adoption behavior of M-Health in developing countries grounded on the unified theory of acceptance and use of technology, dual-factor model, and health belief model.

Method We empirically tested and evaluated the model based on data collected using a survey method from 280 patients living in a developing country. Partial least squares (PLS-SEM) technique was used for data analysis.

Results The results showed that performance expectancy, effort expectancy, social influence, perceived health threat, M-Health app quality, and life quality expectancy have a direct positive effect on patients' intention to use M-Health. The results also showed that security and privacy risks have a direct negative effect on the patient's intention to use MHealth. However, resistance to change was found to have an indirect negative effect on patients' intention to use M-Health through the performance expectancy.

Conclusion The research contributes to the existing literature of health information systems and M-Health by better understanding how technological, social, and functional factors are associated with digital health applications and services use and success in the context of developing countries. With the widespread availability of mobile technologies and services and the growing demand for M-Health apps, this research can help guide the development of the next generation of M-Health apps with a focus on the needs of patients in developing countries. The research has several theoretical and practical implications for the health care industry, government, policy makers, and technology developers and designers. received

April 2, 2019

accepted after revision

August 18, 2019 (c) 2019 Georg Thieme Verlag KG Stuttgart · New York
DOI https://doi.org/

10.1055/s-0039-1697906.

ISSN 1869-0327. 


\section{Background and Significance}

Health information system (HIS) literature continues to grow, investigating how information technology (IT) innovations contribute to more effective health care services. One of the technologies that have grabbed the attention of numerous researchers in the last decade is mobile communication technology in health care. ${ }^{1,2}$ The availability and wide adoption of powerful smartphones and mobile apps may drastically transform the delivery of health care services and information on both organizational and personal levels. Mobile health (M-Health) refers to the use of mobile information and communication technology (ICT) to provide health services and information. The last few years have witnessed an increased availability of M-Health apps that support patient care, monitor patients' vital signs, collect community and clinical health data, encourage healthy behavior, and enhance health information awareness. ${ }^{3}$

The global adoption of mobile communication technologies has resulted in a rapid surge in the mobile apps market. Health care apps are among the most downloaded and used apps in mobile marketplaces, with approximately 1.7 billion users downloading health-related apps in 2017. ${ }^{4}$ According to a recent report, the global M-Health market was $\$ 13.2$ billion in 2016, and it is expected to reach $\$ 46.2$ billion by the year $2021 .^{5}$ This degree of growth brings great opportunities for both health care app developers and providers. Krebs and Duncan $^{6}$ found that most users routinely used M-Health apps daily. In particular, health and well-being apps were heavily used by younger users of high socioeconomic status who are educated and have an overweight to obese body mass index. The prevalence of health apps can be attributed to their potential for improving the efficiency of health care services and reducing the need for direct interaction with health care professionals, which reduces the cost of care delivery. ${ }^{7} \mathrm{M}$ Health integrates mobile technology, medical sensors, and digital communication to enable continuity of care. ${ }^{8}$

The rapid growth in the use of smartphones has opened many opportunities for use in behavioral health care. ${ }^{9}$ Mobile apps are now capable of undertaking a variety of useful tasks, including symptom assessment, psychoeducation, resource location, and tracking of treatment progress. According to the International Telecommunication Union, there are 7.74 billion mobile phone subscriptions in the world, and 6.133 billion of these subscriptions exist in developing countries. ${ }^{10}$ These figures have led to a growing body of literature investigating the opportunities of using mobile phone capabilities in developing countries. Among the different research fields that investigate the applicability and effectiveness of mobile phones, health care emerged as a vigorous research area for developing countries. Given the high penetration rate of mobile phones in developing countries, this technology could provide the means for health care providers to deliver more effective services and better quality of care to larger segments of their population. Applications of M-Health in developing countries include greater access to health care services, diagnosing and monitoring chronic diseases, encouraging healthier living styles, and dissemi- nating public health information. ${ }^{1,11}$ However, evidence is scarce regarding the effect of mobile phones on behavior in general and on health outcomes in particular in developing countries. ${ }^{1,2,12}$ More importantly, M-Health adoption mechanisms and compatibility of M-Health technologies in developing countries are still not clear. ${ }^{12}$

The health care industry in Jordan, the focus of this study, has been recently transformed with emerging technologies to improve its effectiveness. As evidence of its commitment to adopt and diffuse HISs, Jordan's government has implemented a nationwide HIS emphasizing electronic medical records (EMRs) in public and military hospitals. Private hospitals and health clinics are also increasingly adopting HIS to improve health care service quality. Concerning ICT readiness, Jordan has an advanced ICT infrastructure, especially in terms of wireless telecommunication services. ${ }^{13}$ According to Jordan's telecommunication regulatory commission, the number of mobile phone subscribers in Jordan is 16.746 million, which represents a $120 \%$ penetration rate. ${ }^{14}$ This high penetration rate is mainly due to inexpensive wireless services and severe competition among several providers in the Jordanian market. ${ }^{13}$ The availability of this tremendous number of mobile phone subscribers makes MHealth a plausible option for providing health care services to a large segment of the Jordanian population.

\section{Objective}

Despite the technical readiness and wide availability of mobile phones, a major factor for the success of M-Health implementation is patient acceptance of the technology. Therefore, it is important to investigate the factors that affect and contribute to M-Health adoption in Jordan as a case of developing countries. This study aims to answer the following research question: What factors influence patient adoption of M-Health in developing countries? To this end, the study provides an integrative model that explains the adoption behavior of patients with using M-Health based on various relevant theories such as the unified theory of acceptance and use of technology (UTAUT), ${ }^{15}$ the dual-factor model (DFM), ${ }^{16,17}$ and the health belief model (HBM). ${ }^{18}$ The study also provides an empirical investigation of new constructs derived from qualitative interviews, such as privacy and security risk (PSR). The setting of the study is a developing country (Jordan). The study used a convenience sampling method to recruit subjects. The sample was obtained from younger citizens in Jordan who were students at the Jordan University of Science and Technology (JUST). The model has been empirically tested and evaluated based on data collected using a survey method. The survey questionnaire was administered both online and on paper. The questionnaires were distributed among 315 respondents in JUST, and 280 were complete. Partial least square (PLS) structural equation modeling (SEM) was used to test the data using SmartPLS software.

This research makes five specific contributions to the literature. First, it proposes an integrative model that explains the adoption behavior of M-Health by patients in 
developing countries. Second, it is one of the first studies to provide integration between UTAUT, HBM, and DFM models in a single model. In particular, to overcome the limitations of the UTAUT model that focuses only on positive (enabling) factors while ignoring negative (inhibiting) ones, this research integrates the DFM that considers negative factors that may hinder intention to use M-Health. Such inhibitors may be not only important to the M-Health usage decision, but also more important than enabling beliefs. In addition, HBM has been integrated with UTAUT to fully explain adoption behavior from both technology (UTAUT) and health (HBM) perspectives. Third, it provides an empirical investigation for several new constructs that have not been explored in the technology adoption research in developing countries. Fourth, it demonstrates how PSRs negatively influence the adoption behavior of patients in developing countries. Fifth, it provides M-Health app designers and developers with guidelines, criteria, and principles for developing effective M-Health apps.

\section{Theoretical Foundation and Hypothesis Development}

To explain the adoption of M-Health, we conducted interviews with 12 patients using their smartphones to receive health care services, such as with drug reminders and blood pressure management. Based on the content analysis, we have identified four factors influencing their adoption of M-Health: quality of the M-Health application, cost of M-Health, life quality expectancy (LQE), and PSR. These preliminary findings were used in contextualizing the research model. In addition, we identified the other constructs of the model from relevant theories such as UTAUT, DFM, and HBM. Our research model is shown in Fig. 1. Although many previous studies (see
-Supplementary Appendix A, available in the online version) have investigated the patients' adoption behavior of different types of HISs (e.g., electronic health record [EHR], electronic health [e-Health], personal health record [PHR], HIS, and Internet portals), limited studies concerned on the patients' adoption behavior of M-Health apps in developing countries (e.g., Jordan). In particular, limited studies have comprehensively investigated the adoption behavior based on an integrative model grounded on health-related theories (e.g., HBM) and technology-related theories (e.g., UTAUT, DFM). In addition, limited studies have provided a set of design considerations for M-Health app developers and designers, which acts as a guideline for effective M-Health implementation.

\section{UTAUT Model}

Traditionally, technology acceptance models (TAMs) have been used to help explain and predict the adoption of new technologies. In information system research, several theories and models have been proposed to explain the acceptance of the user for new technology and its uses such as $\mathrm{TAM}^{19}{ }^{1}$ innovation diffusion theory (IDT), ${ }^{20}$ theory of reasoned action, ${ }^{21}$ and theory of planned behavior (TPB). ${ }^{22}$ With the intention to formulate a comprehensive model that considers the variables included in all the previous models, Venkatesh and Davis ${ }^{15}$ developed UTAUT. This model accounted for up to 70 percent of the variance in usage intention. Although UTAUT is the most recent adoption theory, it has demonstrated its suitability, generalizability, validity, and reliability in technology adoption studies in different contexts. ${ }^{23-28}$ UTAUT claims that four main factors (performance expectancy [PE], effort expectancy [EE], social influence [SI], and facilitating condition [FC]) determine the intention of using new technology.

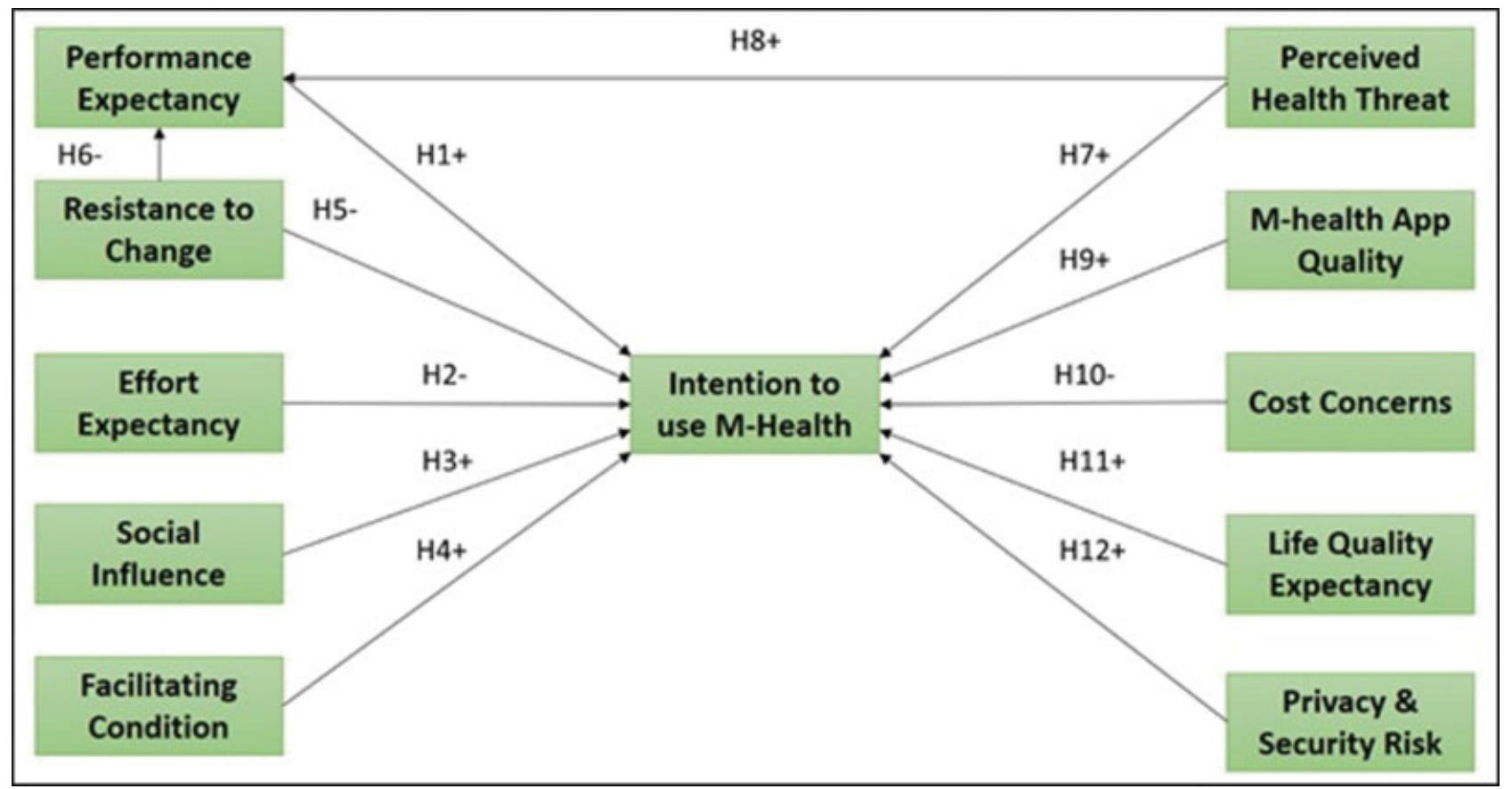

Fig. 1 Research model. 
PE can be defined as the extent to which a patient believes that using M-Health will help them improve job performance. According to Venkatesh and Davis, ${ }^{15}$ PE is reflected in the following five constructs, taken from the previous models: perceived usefulness (TAM/TAM2), extrinsic motivation (motivational model), job-fit (model of personal computer utilization, MPCU), relative advantage (IDT), and outcome expectations (social cognitive theory). Several studies have suggested PE as one of the primary factors that predict the use of $\mathrm{IT}^{1,27-32}$ and even the strongest predictor of the use of IT. ${ }^{15,33}$ For example, Pai and Huang ${ }^{34}$ indicated that PE affects intention to use HIS. Carlsson ${ }^{35}$ revealed that $\mathrm{PE}$ is associated with intention to use mobile devices. In the context of M-Health, this is viewed as the degree to which a patient considers that using mobile devices for health care services will be advantageous. PE in M-Health services is associated with perceived benefits of these services, including reduction of medication and transportation costs, facilitating communication with professionals, and monitoring and diagnosing of chronic diseases, which suggests that patients evaluate M-Health services regarding efficiency based on the costs and benefits they offer. In other words, if patients feel that M-Health services are useful and will improve health outcome, enhance management of their health conditions, and assist them in increasing their quality of life, this usefulness will contribute to their intention to use those services.

Thus, we propose the following hypothesis.

H1: PE has a positive effect on patient intentions to use M-Health.

EE is defined as the degree of ease a patient feels with respect to the use of M-Health. According to Venkatesh and Davis, ${ }^{15}$ the three previous constructs that represent EE are perceived ease of use (TAM/TAM2), complexity (MPCU), and ease of use (IDT). Extensive empirical evidence has shown that EE has a direct effect on usage intention for technology adoption. ${ }^{31,36,37}$ For example, it was found that EE is a determinant of users' intention to use e-Health services, clinical decision support systems, and M-Health. ${ }^{38,39}$ Since M-Health is in its infancy in developing countries, it is believed that EE will be an important determinant of intention to use its services. At early stage of diffusion, the use of smart phones for health care services may be characterized by physical and mental efforts. Therefore, when patients do not find a particular system easy to use, helpful in completing tasks, comfortable, and convenient, they will usually reject using that system, which results in a system failure. In addition, the discomfort of patients in using their mobile phones and mobile apps generally makes it harder to use M-Health apps, making the apps less acceptable and less desirable. Accordingly, the adoption of M-Health apps depends on whether the apps are easy to use and free of effort. The more learning effort is required to use MHealth apps, the more resistance would there be on the part of the patient to use them. If the use of M-Health apps involves tedious training, documentation, registration, and learning about service terms and conditions, then the interaction with them would not be clear and understandable, which would hinder the patients' adoption of M-Health.
Therefore, we propose the following hypothesis.

H2: EE has a negative effect on patient intentions to use M-Health.

SI is defined as the extent to which a patient perceives that significant others believe they should use M-Health. It underlies the aspects of subjective norm (TRA, TAM2), social factors (MPCU), and image (IDT).$^{15} \mathrm{SI}$ is based on the notion that an individual's behavior is influenced by the way in which one believes others will view him/her as a result of having used M-Health services. Thus, friends, relatives, and peers in the society may influence patients' decisions to use M-Health. ${ }^{28,32}$ Dwivedi et al $^{40}$ argued that SI is relevant in the M-Health technology context because interaction with M-Health technology is likely to be observed by others in daily life, and that aspirational reference group's influence will lead to the adhesion of using the technology. Existing research on information systems has found a significant relationship between SI and adoption of information systems. ${ }^{31,36}$ For example, Sun et $\mathrm{al}^{38}$ found that SI affects the behavioral intention to use M-Health services. Wills et $\mathrm{al}^{41}$ reported that a significant corelationship exists between SI and users' behavioral intention to use digital information in health care.

Therefore, we propose the following hypothesis.

H3: SI has a positive effect on patient intentions to use M-Health.

FC is the degree to which a patient believes that an organizational or technical infrastructure exists to support the use of M-Health. FC is derived from perceived behavioral control (TPB, TAM-TPB), FCs (MPCU), and compatibility (IDT). ${ }^{15}$ Bhattacherjee and Hikmet ${ }^{47}$ found that infrastructure support plays a critical role in HIS usage. It was reported that FC is positively associated with the behavioral intention of using smartphones for health services. ${ }^{23,39}$ Patients must have the ability, knowledge, and resources necessary to use M-Health. The effective use of M-Health services by patients hinges on the availability of organizational resources and appropriate technical infrastructure required for their optimum performance. This implies that the degree to which patients believe that organizational resources and technical infrastructure exist to support the effective use of M-Health services could determine if they will actually use their smart phones for health care services or not. Some patients are hesitant about adopting M-Health due to lack of resources and technical support. Therefore, we expect that perceived facilitating resources, including technical support, organizational resources, and knowledge, will positively influence the intention to use M-Health.

Therefore, we propose the following hypothesis.

H4: FCs have a positive effect on patient intentions to use M-Health.

\section{Dual-Factor Model}

To overcome the limitations of traditional TAMs that focus only on positive factors while ignoring negative ones, Cenfetelli ${ }^{16,17}$ developed a DFM of IT use. A large body of existing research in information systems has explored overall beliefs about system usage, antecedents of system satisfaction, and 
other perceptions that enable system success, create positive attitudes, and encourage use. ${ }^{24,25,31,36}$ However, less attention has been given to what perceptions uniquely inhibit use. In particular, research on HIS adoption has long focused on "enablers" or positive factors that drive adoption such as PE and SI, as proposed by IT adoption models such as TAM, ${ }^{19}$ UTAUT, ${ }^{15}$ and IDT $^{20}$ with a little attention to understanding the "inhibitors" or negative factors that hinder adoption. ${ }^{28,43}$ This focus has resulted in a pro-innovation bias in IT/HIS adoption research-a frequently mentioned problem in IT/ HIS adoption research. ${ }^{44}$ As a consequence of this problem, the current IT adoption models provide reasonably good explanations of adoption behaviors; however, they cannot adequately explain rejection behaviors. For instance, although the use of advanced HISs by physicians such as computerized physician order entry systems and EMR systems are expected to reduce medical errors and improve medical service delivery as reported in Lapointe and Rivard, ${ }^{45}$ many physicians tended to reject these systems which resulted in systems failure. In addition, Freudenheim $^{46}$ reported in his case study at the prestigious Cedars-Sinai Medical Center at Los Angeles that physicians rebelled against a newly installed computer system, complaining that the system was too great a distraction from their medical duties and forcing its withdrawal after the system was already online in two-thirds of the 870-bed hospital.

To fill this gap, the DFM considers both positive (enabling) and negative (inhibiting) factors to examine IT use. Such inhibitors may be not only important to the IT usage decision, but also more important than enabling beliefs. Cenfetelli ${ }^{16,17}$ argued in his model that IT adoption decisions among potential adopters are based on simultaneous considerations of both enabling and inhibiting factors. Cenfetelli suggested that inhibitors are not quite the opposite of enablers, but are qualitatively distinct constructs that are independent of but may coexist with enablers. While IT adoption is best predicted by enablers, IT nonadoption tends to be best predicted by inhibitors. There is empirical evidence that negative perceptions do inhibit usage. For example, Bhattacherjee and Hikmet ${ }^{47}$ found that user resistance to change (RTC) hinders physicians' intent to adopt HISs. Cenfetelli ${ }^{16,17}$ did not suggest any specific inhibitor of IT adoption, and the choice of inhibitors may depend on the specific research context and technology being examined. However, one prominent inhibitor that emerged recently was RTC. ${ }^{27}$

For the past three decades, information system research has extensively investigated concepts related to the technology use and adoption while giving less attention to technology resistance topics. Research in this topic is still somewhat immature. ${ }^{48}$ Prior research in information systems suggested a lack of research on factors that influence technology resistance. ${ }^{45,49}$ Change is a transition from the present to future. Change and RTC move hand-in-hand. With the initiation of a new program, people may automatically attempt to resist, which many times may cause a total or partial failure of the program and its objectives. RTC will have normally negative effects in the implementation of projects and programs. Change produces anxiety and uncertainty. When changes are instigated, users are affected. As a result, RTC often occurs. ICT change is mainly related to the emergence of innovations that require the users to adopt new technologies, processes, and practices.

In the context of health care, $R T C$ refers to a patient's attempt to maintain previous behaviors and habits in the face of change. ${ }^{50}$ In other words, technology resistance is represented as an action or intentional inaction that opposes the implementation of new technology. ${ }^{48}$ Prior information system research explained technology resistance based on beliefs and attitudes toward the technology. ${ }^{17,45}$ The main beliefs explored in information system research include perceived threats, technology inhibitors, and loss of power. Technology resistance is found to be a prominent reason for system failure. $^{27,30,47}$

Cenfetelli contended that inhibitors influence IT adoption both directly and indirectly via enablers as mediators. The indirect effect suggests that inhibitors tend to influence (or "bias") adopters' perception of enablers in a negative manner. RTC is independent of but may coexist with enablers such as PE (expected benefits from system adoption). Lapointe and Rivard ${ }^{45}$ suggested that users evaluate technology in terms of its features, perceived value, and associated threat, and based on this evaluation users can make projections about the intention to accept or the intention to resist the technology. Nkosi and Mekuria ${ }^{31}$ found in their study that RTC is the inhibitor for IT usage by physicians that has a significant direct influence on both intention and perceived usefulness. Another study of older people's acceptance of preventive M-Health services in China found a significant influence of RTC on perceived usefulness, not behavioral intention. ${ }^{51}$ As patients were used to their familiar disease management and diagnosis model, "social inertia" would likely cause them to have negative cognitive and emotional responses to the new smartphone health technology; thus, they may give a relatively low evaluation of the technology's usefulness.

Thus, we propose the following hypotheses.

H5: RTC has a negative effect on patient intentions to use M-Health.

H6: RTC has a negative effect on the PE of M-Health.

\section{Health Belief Model}

To differentiate the adoption behavior of HIS (e.g., M-Health) from other technologies, researchers need to pay attention to adapting a theory specifically to the health care context. ${ }^{52}$ One way to achieve this adaptation is by integrating the health behavior theories (e.g., $\mathrm{HBM}^{18}$ ) with the technology adoption theories (e.g., UTAUT ${ }^{15}$ ) to provide a fully comprehensive understanding of the adoption behaviors. Although many past studies on IT use for health-related purposes adopted the UTAUT or HBM, ${ }^{28,53}$ the use of these theories independently has not been able to fully explain IT adoption behavior. The UTAUT has been used to predict an individual's technology use and is most commonly used for studying technology-related behavior; however, it is an inadequate model for health-related behavior. ${ }^{15,42}$ In other words, the 
UTAUT views health-related IT use behavior from the technology perspective. The HBM attempts to explain the factors that influence health-related IT use purely from the health perspective; however, it fails to explain the mechanism or the process that leads to the behavior. ${ }^{18,42}$ In addition, the literature shows that health behavior theories have been quite often included to some extent in the constructs determining adoption of a technology. ${ }^{15,42}$ To fill this gap, HBM has been integrated with UTAUT to explain adoption behavior from both technology and health perspectives. UTAUT's effect on IT use for health-related purposes could only be fully understood by incorporating dimensions of the HBM that explain individuals' belief about health into the model. In short, there is a need to examine health-related IT use from an integrated perspective that combines cognition, attitude, and behavior as well as the subjective evaluation of the psychological states of individuals regarding their perception of their health status.

The HBM was originally developed by several social psychologists of the U.S. Public Health Services in the 1950s. ${ }^{18}$ HBM is a psychological health behavior change model developed to explain and predict health-related behaviors, particularly in regard to the uptake of health services. The basic assumption of the HBM is that in the absence of any symptoms, individuals will not take health or preventive measures unless they are psychologically ready (e.g., they feel vulnerable to a disease). HBM suggests that people's beliefs about health threats, perceived benefits of action and barriers to action, and self-efficacy explain engagement or lack of it in health promotion behavior. ${ }^{18}$

In essence, the adoption of M-Health is patients' behavior to promote, protect, or maintain their own health. ${ }^{38} \mathrm{HBM}$ suggests that belief in a health threat predicts the likelihood of engaging in health behavior. ${ }^{18}$ In this study, perceived health threat (PHT) refers to patients' awareness and care of a health condition and its potential consequences. Specifically, PHT is assessed according to perceived susceptibility and perceived severity. Perceived benefits and perceived barriers are modeled as PE and RTC in our research. If susceptibility is accepted, this will impact a patient's perceived benefits of taking an action as well as the perceived barriers of taking action. Ultimately, cues to action will determine a patient's health behavior. ${ }^{54}$ In particular, patients who perceive a health threat are more likely to change their health behavior such as using ICT (e.g., mobile phones) to satisfy healthrelated information needs. Thus, we argue that PHT is an important and noticeable predictor in determining patients' behavior. Patients who perceive their health to be at risk would be expected to have a positive attitude toward Mhealth use for health purposes. In addition, patients who believe that the app is useful for providing information on health and health management once health threats occur would have a positive attitude toward its use. In other words, cognitive and affective beliefs toward M-health become central to a person who perceives his/her health to be at risk or is conscious about his/her health. Therefore, these patients would have greater intention to use the M-Health apps. According to the previous literature, a PHT has both direct and indirect influences on a consumer's intention to use health IT through perceived usefulness. ${ }^{30,31}$

Thus, we propose the following hypotheses.

H7: PHT has a positive effect on patient intentions to use M-Health.

H8: PHT has a positive effect on PE of M-Health.

\section{M-Health App Quality}

App quality $(Q)$ refers to a patient's positive evaluation of an app's features, ensuring they meet users' needs and reflect the overall excellence of the app. Three dimensions of $\mathrm{Q}$ have been identified based on the findings of the interviews we conducted: technical adequacy, content, and appearance.

Technical adequacy includes the type, level of detail, and variety of information, which are determined during the system design and development phase, whereas timeliness, accuracy, and reliability result from the system operations. 55 It is also represented by accessibility, flexibility, convenience of access, and response time, ${ }^{56}$ which are important for explaining the effectiveness of the system. The quality of content includes accuracy, relevance, adequacy, and understandability of contents. The content of M-Health apps should be valuable, updated, and sufficient. The content quality influences the user's perceptions of the value of the apps and their importance to their wellbeing and therefore it is important for the adoption of the M-Health apps. Appearance quality includes quality of format, timeliness of reports, the manner of presentation, and the result of information. ${ }^{57}$ The appearance quality is a critical usable factor influencing users' use of M-Health apps because of the small screen and inconvenient input. ${ }^{58}$ To provide the users with understandable information, M-Health apps must include short and concise textual descriptions accompanied by pictures and multimedia content. ${ }^{59}$

Floh and Treiblmaier ${ }^{60}$ emphasized that system quality, which includes web design, structure, and content, is an important factor for achieving customer satisfaction. Schaupp et $\mathrm{al}^{61}$ conducted a survey to investigate the impact of information quality and system quality on satisfaction. The results showed that information quality and system quality were significant predictors of satisfaction, and, therefore, intention to use the system. ${ }^{62}$ In addition, Li and Jiao ${ }^{63}$ confirmed that there is a significant relationship between system quality and user satisfaction and that this relationship affects the actual use of online services. In addition, system quality perceptions have been reported to affect behavioral intention and usage decisions in many studies. ${ }^{55,64,65}$ Users of mobile devices desire quality app that satisfies their functional requirements. When users are not satisfied with an app's quality, their negative word of mouth can have an adverse impact on it. ${ }^{66}$ Any problem in the MHealth Q may result in the withdrawal of users. ${ }^{67}$ Similarly, a high-quality M-Health app may result in the perception that one's experience is fun and enjoyable. Patients are likely to experience greater enjoyment and have more fun completing a given task at an app with high quality in terms of informationrelated as well as health-related attributes. Consequently, it is evident that the quality of M-Health app that provides health 
care services is an essential factor and needs to be investigated and included in the proposed model. M-Health design of a professional standard with high quality will promote patient satisfaction and facilitate adoption.

Thus, we propose the following hypothesis.

H9: $Q$ has a positive effect on patient intentions to use M-Health.

\section{Cost Concerns}

Cost concerns (CCs) refer to the degree to which the patient recognizes the possible expenses of using M-Health, such as equipment costs ${ }^{68}$ as well as its financial liabilities. CCs have three sub-themes based on the findings from our interviews: infrastructure cost, reimbursement, and cost-benefit. According to behavioral decision theory, ${ }^{68}$ the cost-benefit pattern is significant to the use of the technology. If patients perceive that the benefits of M-Health outweigh the cost of investment and they have sufficient financial resources, then these patients would bring a positive attitude toward using M-Health. Yarbrough and Smith ${ }^{69}$ stated that the cost factor had been largely omitted in the prior literature. Moreover, Aydın and Özer ${ }^{70}$ discussed the important role of switching cost on customer loyalty in their national customer satisfaction indices. Even though M-Health adoption provides better service quality and enhances effectiveness of clinical function, the investment in M-Health technology is expected to be costly. The overall cost of M-Health includes the cost not only of the devices but also of infrastructure, configuration, downloading, and maintenance costs. ${ }^{68}$ Further, the cost may include the learning cost, which is the effort needed to learn about the new service/product. ${ }^{71}$ In addition, experiences with technical problems, such as slow connections, poor quality, delay, and missing links, could make users frustrated. Hence, the cost might be one of the factors for users to hesitate for M-Health acceptance. In fact, if a patient considers the cost for using a new M-Health app high, he/she will be reluctant to the actual use. Thus, the high cost of value-added services provided by M-Health apps might negatively affect the intention to adopt the technology. Ho Cheong and Park ${ }^{72}$ extended the TAM by adding the perceived cost factor to examine the intention to use mobile internet (M-Internet) in Korea. Some researchers argued that access cost, equipment costs, and transaction fees are important factors that create perception in users' mind that a mobile device (M-device) is expensive to use which negatively influences its adoption. ${ }^{8,72,73}$ Previous studies have also shown that cost is a highly significant predictor of usage intention and its influence is stronger than privacy concerns. $^{74,75}$

Thus, we propose the following hypothesis.

H10: CCs have a negative effect on patient intentions to use M-Health.

\section{Life Quality Expectancy}

Quality of life technology is primarily designed to optimize the health and independent functioning of patients. ${ }^{76,77}$ M-Health is considered one of those technologies. M-Health systems could help manage medication, including dispens- ing, adherence, and tracking. M-Health apps monitor health conditions such as glucometers and blood pressure monitors; provide assistive technologies that compensate for sensory, physical, and cognitive impairments; improve cognitive fitness such as through thinking games and challenging puzzles; and enable individuals to communicate, organize, and share information and resources with each other. Expectations are high for M-Health services. About half of patients recently surveyed by Price Waterhouse and Coopers $^{78}$ predict that M-Health will improve the convenience, cost, and quality of health care in the next 3 years, and $96 \%$ of current M-Health app users believe the apps help improve their quality of life. ${ }^{79} L Q E$ refers to the degree to which a patient perceives that M-Health improves their independence and fits their lifestyle properly. LQE has three sub-themes based on the findings from our interviews: independence, lifestyle, and quality of life. As people age, they often lose some of their ability to manage on their own. M-Health can help people remain independent by monitoring their abilities and providing assistance when needed. This technology could help with a variety of tasks or activities and provide assistance at varying levels of intensity from simple passive monitoring to providing feedback, evaluation, and coaching, to help patients with a task or to perform the entire task on their behalf. An effective integration of M-Health apps could also improve patients' quality of life by enabling safer independent living and increased social inclusion. For example, M-Health could help older and disabled people to remain in their own homes for longer by providing them and their caregivers with increased safety and reassurance, reducing social isolation, and supporting treatment, rehabilitation and intermediate care. Indeed, patients' management of their own chronic conditions and active engagement in their health care are associated with improved independence and life quality, and reduced health care utilization and cost. ${ }^{80,81}$

Quality of life can be explained in terms of perceived benefits and a possible change in lifestyles. ${ }^{24}$ Patients would treat M-Health as a safety-net system that provides assistance in emergency situations. In many cases, patients would need to spend most of the day independently, and they could greatly benefit from the ability of M-Health to provide remote help in case of accidents. This is of utmost importance for people who live in remote and rural areas in developing countries and who do not have easy access to providers. Culley et $\mathrm{al}^{82}$ found that technology use may improve the quality of life among patients by promoting interaction with their families and friends and communication with health care providers.

Therefore, we propose the following hypothesis.

H11: LQE has a positive effect on patient intentions to use M-Health.

\section{Privacy and Security Risk}

The collection and use of a wide variety of personal data, including health data, by mobile apps increase the concerns about privacy and security. ${ }^{83}$ In 2015, the U.S. Department of Health and Human Services reported that due to large data 
breaches in 2014 alone, the privacy of approximately 21.4 million individuals was compromised. Some of these privacy breaches were widely publicized and multiplied the concerns that patients have regarding the use of M-Health. ${ }^{84,85} \mathrm{~A}$ perceived need for privacy tended to be more important in situations where individuals did not feel comfortable with the possibilities of release of information to untrusted parties.

Westin $^{86}$ defined information privacy as the ability of individuals to determine and control the level of information that is revealed or communicated to others. Today, concerns about personal data are among the most common reasons why some mobile device users avoid downloading mobile apps requiring access to personal data. The adoption of M-Health apps requires the patients to continuously provide sensitive data. Patients do not usually like to be watched or monitored. Privacy is typically assumed in situations where individuals are not aware that it can be violated. According to Dehzad et $\mathrm{al}^{87}$ there is a degree of lack of interest on the part of both patients and health care providers to adopt M-Health apps due to concerns over security and privacy issues. Patients should know who collects what information and how it is going to be used. M-Health that builds on wireless networks will be more vulnerable to security attacks and interceptions.

Understanding how security concerns and privacy expectancy of the M-Health apps affect the adoption of M-Health apps is important. Developing countries face steady growth in the prevalence of chronic conditions. Kahn et al ${ }^{1}$ examined various M-Health apps and defined the risks and benefits of each. They found positive examples but little solid evaluation of clinical or economic performance, which highlights the need for such an evaluation.

To enhance the capabilities and the use of M-Health apps, developers often include new functions before they are appropriately developed or tested, which jeopardizes the security and privacy of the app users. Such practices often concern the users and may potentially lead them to form negative impressions about the app and lower the potential for continual use. ${ }^{88,89}$ Mobile devices are being considered as service platforms for health care delivery, access, and communication. However, mobile services face challenges with regard to delivering secure multimedia-based health services due to limitations in computation power. Since mobile devices have limited computational capacity and run on small batteries, they are unable to run heavy multimedia and security algorithms. Laxman et $\mathrm{al}^{90}$ studied consumer health informatics and found privacy and security concerns to be an obstacle, despite consumer's general willingness to adopt consumer health informatics. Angst and Agarwal ${ }^{91}$ found concerns for privacy information to be an important influencer on individual's attitude to use EHR. Becker ${ }^{92}$ identified a prevalent concern of unwanted disclosures of personal information throughout his study on young consumers' acceptance of mobile mental health treatment applications.

Thus, we propose the following hypothesis.

H12: PSRs have a negative effect on patient intentions to use M-Health.

\section{Research Method}

\section{Research Setting}

The target population for this study was younger citizens in Jordan. This study used a convenience sampling method to recruit subjects, which is "a type of nonprobability sampling which involves the sample being drawn from that part of the population which is close to hand." ${ }^{93}$ Moreover, it is cost effective and has been widely used in information systems research. ${ }^{53,94,95}$ The sample was obtained from younger citizens in Jordan who were students at JUST. JUST offers 143 undergraduate and graduate degrees through its 15 schools and institutes. More than 23,000 students are currently enrolled at JUST. JUST ranked among the top 400 universities worldwide according to the Times Higher Education and ranked first locally according to the U.S. News in 2019. JUST students were considered to be suitable for this study because of their comfort as millennials with the use of mobile technologies for activities such as searching for information, gaming, and communication. In addition, the university includes many health-related schools (such as medicine, pharmacy, dentistry, and applied health schools) and many IT-related schools (such as IT, engineering, and science schools), which means that the university's students are either more health aware or technology aware or both. In particular, the majority of current JUST students use their smartphone for receiving health care services and this is confirmed by our results that two-thirds of the students are actual users for certain M-Health applications. Further, literature shows that the student population is constantly used in M-Health research and college students are familiar and comfortable with different types of M-Health platforms. ${ }^{53,94,96,97}$

\section{Procedure}

Prior to commencing the research, ethical approval was sought and obtained. We also contacted the deans of different schools to seek permission to collect data from students. All participants in the research were given consent forms and information sheets that clearly explained the purpose of the study. Respondents were also made aware of their rights to withdraw participation at any time during the study. Respondents were also made aware of the fact that they may request the findings of the research once it is completed.

To collect the data, a survey questionnaire was administered both online and on paper. To ensure that the subjects were recruited from all the schools of the university, a clustered random sampling method was used to target students. ${ }^{98}$ In particular, paper-based survey questionnaires were given to some faculty members to distribute among their students (e.g., medicine, applied health science, and IT schools). As it was hard to target other schools' students using the paper questionnaires, an online survey was posted by vice deans of these schools into their official online communities (e.g., online groups of nursing, engineering schools). As an advertisement to motivate the participation in the study, an email was forwarded to the mailing list of the university's students to check their online groups for details about the study and fill out the online survey. To ensure that 
participants clearly understood the objectives of the research survey, the functions and characteristics of M-Health were explained before the survey was administered. Furthermore, the participants were informed that the survey would take 10 minutes to complete. The survey was conducted from June to September 2018. Overall, the survey questionnaires were distributed among 315 respondents in JUST, and 287 were returned to the researcher. However, seven incomplete questionnaires were excluded from the study. This represents an $89 \%$ response rate.

To test whether the sample size could provide sufficient power for testing the proposed research model, we conducted power analysis using two different approaches: 10 times rule of thumb strategy and Cohen's sample size recommendation using $\mathrm{G}^{*}$ Power. $^{99}$ Both methods have been widely used by previous studies using PLS. ${ }^{100,101}$ Based on the 10 times rule of thumb strategy, we needed a minimum of 100 participants for the study. According to Cohen's sample size recommendation, we needed at least 79 participants to achieve $R^{2}$ values of around 0.50 at a significance level of $1 \%$ and a statistical power of $80 \%$. Accordingly, our sample size meets the criteria of both approaches.

\section{Survey Instruments}

The survey instruments for four constructs, including MHealth Q, CCs, LQE, and PSR, were adapted from the qualitative interview and related literature. The survey instruments for the other constructs in the research model were adapted from the relevant theories such as UTAUT, ${ }^{15} \mathrm{HBM},{ }^{18}$ and DFM. ${ }^{16}$ All the items have been modified to make them relevant to the context of M-Health (- Supplementary Appendix B, available in the online version). The finalized survey questionnaire consists of three main parts: background introduction, demographic information, and perception of M-Health. In the background introduction, we explain M-Health and illustrate real-world scenarios to subjects. The items of the constructs were measured using five-point Likert scale questions with answer choices ranging from (1) "strongly disagree" to (5) "strongly agree."

\section{Data Analysis}

Data from questionnaires were inserted into Microsoft Excel and imported into SmartPLS 3.2.7 software, ${ }^{102}$ a technique of SEM, for statistical analysis. SEM is a widely accepted paradigm to gauge the validity of meaty theories with empirical data. ${ }^{103,104}$ It is an extensive statistical representation of general linear modeling. ${ }^{105,106}$ One of the notable applications of SEM is that it can be applied to explore the relationships among latent constructs to determine which are indicated by multiple measures. ${ }^{107}$ SEM is composed of two evaluation models: measurement model and path model. ${ }^{108}$ The path model is an extensive form of a multiple regression model in which various multiple regressions are estimated simultaneously. ${ }^{109}$ In other words, path analysis can be regarded as a special case of SEM in which the structural relations among latent variables are molded. ${ }^{106,109}$

There are two approaches for SEM: the first is a covariance-based analysis (CB-SEM) used in AMOS and Lisrel, and the second is a variance-based approach used in PLS. The decision to utilize one of the two approaches depends on the characteristics of the data and the model being tested. According to Reinartz et al, ${ }^{110}$ when the focus of the research is on prediction and theory development, PLS is more appropriate. Therefore, the reason for utilizing PLS in this research is because we aim to predict factors that influence M-Health acceptance in a predictive model rather than a theory confirmatory model. An advantage of PLS is its ability to estimate the loadings of indicators on constructs and the causal relationships among constructs in multistage models even when the research sample is relatively small. ${ }^{111,112}$ Even more, the PLS method is considered robust against skewed distributions, multicollinearity, and misspecification of the structural model. ${ }^{113-115}$ The literature on technology acceptance in different disciplines, especially research which utilized the UTAUT model, has regularly relied on PLS for model testing. ${ }^{116-119}$

\section{Results}

\section{Sample Characteristics}

-Table 1 provides a general demographic overview of the respondents who participated in this study in terms of gender, age, and educational level. Among the 287 responses that were received, 280 were complete and valid, which was greater than the number suggested by power analysis, as discussed in the Procedure section.

As shown in -Table 1, males accounted for $57 \%$ of the participants, the majority of the participants belonged to the 18 to 33 -year-old age group (69\%), and about three-quarters of the participants were undergraduate students (76\%). The statistics also show that all the participants used smartphones for different tasks and that about two-thirds of the respondents had used at least one M-Health app for receiving certain health care services. Such a result shows that the majority of the sample respondents are actual users of MHealth. The diversity of the participants is beneficial for the purpose of this study. ${ }^{120,121}$

\section{Evaluation of the Measurement Model}

The measurement model (a confirmatory factor analysis [CFA] model) specifies the relationships that suggest how measured variables represent a construct that is not measured directly. ${ }^{122}$ It was assessed with CFA using the SmartPLS tool to examine convergent and discriminant validity. In the CFA, the convergent validity relied on three indicators: the item reliability of each measure (factor loading), the reliability of each construct, and the average variance extracted (AVE). Constructs have convergent validity when the composite reliability (CR) exceeds the criterion of 0.70 and the AVE is above $0.50 .^{41}$ - Table 2 shows the factor loadings, the AVE, the CR, and the Cronbach's alpha values. All item loadings are bigger than 0.7 , and $t$-values indicate that all loadings are significant at 0.001. All AVEs were above 0.5 , and all the CRs were above 0.7 . Therefore, the results support the convergent validity of the scales. ${ }^{122,123}$ In addition, all $\alpha$ values are larger than 0.7 , revealing good reliability. ${ }^{124}$ 
Table 1 Description of demographic profile

\begin{tabular}{|l|l|l|l|}
\hline Variable & & $N$ & $\%$ \\
\hline \multirow{3}{*}{ Gender } & Male & 160 & 57 \\
\cline { 2 - 4 } & Female & 120 & 43 \\
\hline \multirow{3}{*}{ Age } & $18-33$ & 195 & 69 \\
\cline { 2 - 4 } & $34-49$ & 65 & 24 \\
\cline { 2 - 4 } & Greater than 50 & 20 & 7 \\
\hline \multirow{2}{*}{ Education Level } & Bachelor's degree & 215 & 76 \\
\cline { 2 - 4 } & Graduate degree & 65 & 24 \\
\hline
\end{tabular}

To assess for discriminant validity, the square root of the AVE for each construct was compared with the interfactor correlations between that construct and all other constructs. If the
AVE is higher than the squared interscale correlations of the construct, then it shows good discriminant validity. ${ }^{122,123}$ As shown in -Table 3, for each factor, the square root of AVE is larger than the correlation coefficients with other factors, and this confirms sufficient discriminant validity.

\section{Evaluation of the Structural Model}

As previously mentioned, the second step is to assess the structural model, which includes the testing of the theoretical hypothesis and the relationships between latent constructs provided through the employed SEM technique and the use of the SmartPLS software. The test of significance of all paths was done using the bootstrap resampling procedure, a nonparametric technique for estimating the precision of the PLS estimates. The test statistics indicate whether the relationship is statistically different from zero, and the

Table 2 Item loadings, AVE, composite reliabilities, and alpha

\begin{tabular}{|c|c|c|c|c|c|c|}
\hline & Item & Loading & AVE & CR & $R^{2}$ & Cronbach's alpha \\
\hline \multirow[t]{3}{*}{ Cost concerns } & CC1 & 0.645 & 0.823 & 0.899 & & 0.934 \\
\hline & $\mathrm{CC} 2$ & 0.763 & & & & \\
\hline & CC4 & 0.923 & & & & \\
\hline \multirow[t]{4}{*}{ Effort expectancy } & EE1 & 0.878 & 0.775 & 0.912 & & 0.895 \\
\hline & EE2 & 0.802 & & & & \\
\hline & EE3 & 0.773 & & & & \\
\hline & EE4 & 0.845 & & & & \\
\hline \multirow[t]{3}{*}{ Resistance to change } & RTC1 & 0.927 & 0.755 & 0.844 & & 0.801 \\
\hline & RTC2 & 0.865 & & & & \\
\hline & RTC3 & 0.879 & & & & \\
\hline \multirow[t]{4}{*}{ Privacy and security risk } & PSR1 & 0.909 & 0.756 & 0.799 & & 0.852 \\
\hline & PSR2 & 0.867 & & & & \\
\hline & PSR3 & 0.767 & & & & \\
\hline & PSR4 & 0.653 & & & & \\
\hline \multirow[t]{3}{*}{ Intention to use M-Health } & ITU1 & 0.965 & 0.945 & 0.987 & 0.59 & 0.952 \\
\hline & ITU2 & 0.975 & & & & \\
\hline & ITU3 & 0.964 & & & & \\
\hline \multirow[t]{4}{*}{ M-Health app quality } & Q1 & 0.801 & 0.765 & 0.856 & & 0.803 \\
\hline & Q2 & 0.834 & & & & \\
\hline & Q3 & 0.747 & & & & \\
\hline & Q4 & 0.867 & & & & \\
\hline \multirow[t]{4}{*}{ Life quality expectancy } & LQE1 & 0.912 & 0.678 & 0.879 & & 0.821 \\
\hline & LQE2 & 0.802 & & & & \\
\hline & LQE3 & 0.856 & & & & \\
\hline & LQE4 & 0.922 & & & & \\
\hline \multirow[t]{4}{*}{ Perceived health threat } & PHT1 & 0.923 & 0.845 & 0.962 & & 0.923 \\
\hline & PHT2 & 0.903 & & & & \\
\hline & PHT3 & 0.945 & & & & \\
\hline & PHT4 & 0.911 & & & & \\
\hline
\end{tabular}

(Continued) 
Table 2 (Continued)

\begin{tabular}{|l|l|l|l|l|l|l|}
\hline & Item & Loading & AVE & CR & $R^{2}$ & Cronbach's alpha \\
\hline \multirow{5}{*}{ Performance expectancy } & PE1 & 0.845 & 0.806 & 0.900 & 0.36 & 0.879 \\
\cline { 2 - 7 } & PE2 & 0.827 & & & & \\
\cline { 2 - 7 } & PE3 & 0.823 & & & & \\
\cline { 2 - 7 } & PE4 & 0.807 & & & & \\
\hline \multirow{5}{*}{ Facilitating condition } & FC1 & 0.645 & 0.614 & 0.790 & & 0.752 \\
\cline { 2 - 7 } & FC3 & 0.642 & & & & \\
\cline { 2 - 7 } & FC4 & 0.856 & & & & \\
\hline
\end{tabular}

Abbreviations: AVE, average variance extracted; CC, cost concern; CR, composite reliability; EE, effort expectancy; FC, facilitating condition; ITU, intention to use M-Health; LQE, life quality expectancy; M-Health, mobile health; PE, performance expectancy; PHT, perceived health threat; PSR, privacy and security risk; Q, M-Health app quality; RTC, resistance to change; SI, social influence.

Table 3 AVE scores and correlation of latent variables

\begin{tabular}{|l|l|l|l|l|l|l|l|l|l|l|l|}
\hline & CC & EE & RTC & PSR & ITU & Q & LQE & PHT & PE & FC & SI \\
\hline CC & $\mathbf{0 . 9 0 7}$ & & & & & & & & & & \\
\hline EE & 0.143 & $\mathbf{0 . 8 8 0}$ & & & & & & & & & \\
\hline RTC & 0.076 & 0.124 & $\mathbf{0 . 8 6 8}$ & & & & & & & & \\
\hline PSR & -0.07 & -0.087 & 0.235 & $\mathbf{0 . 8 6 9}$ & & & & & & & \\
\hline ITU & -0.03 & 0.435 & 0.122 & 0.23 & 0.972 & & & & & & \\
\hline Q & 0.035 & 0.088 & 0.087 & 0.359 & 0.139 & $\mathbf{0 . 8 7 4}$ & & & & & \\
\hline LQE & -0.019 & 0.324 & 0.156 & -0.201 & 0.513 & 0.034 & $\mathbf{0 . 8 2 3}$ & & & & \\
\hline PHT & 0.009 & 0.067 & 0.235 & 0.331 & 0.202 & 0.418 & 0.032 & 0.919 & & & \\
\hline PE & 0.06 & 0.423 & 0.119 & -0.036 & 0.523 & 0.202 & 0.591 & 0.187 & 0.897 & & \\
\hline FC & 0.231 & 0.235 & 0.058 & 0.231 & 0.231 & 0.363 & -0.042 & 0.538 & 0.231 & 0.783 & \\
\hline SI & -0.098 & 0.397 & 0.267 & 0.078 & 0.439 & 0.189 & 0.419 & 0.312 & 0.567 & 0.163 & $\mathbf{0 . 9 1 8}$ \\
\hline
\end{tabular}

Abbreviations: CC, cost concern; EE, effort expectancy; FC, facilitating condition; ITU, intention to use M-Health; LQE, life quality expectancy; PE, performance expectancy; PHT, perceived health threat; PSR, privacy and security risk; Q, M-Health app quality; RTC, resistance to change; SI, social influence.

results are reported in -Table 4 . The structural model gives information as to how well the theoretical model predicts the hypothesized paths or relationships. It is estimated by the path coefficients and $R^{2}$ values, as shown in - Fig. 2. $R^{2}$ indicates the percentage of the variance in the corresponding construct that is explained by the structural paths leading to it. The path coefficients indicate the strengths of relationships between constructs. ${ }^{100}$

Overall, the results of the proposed research model show a good fit: $\left(X^{2}=601.15, \mathrm{df}=312, X^{2} / \mathrm{df}=1.654, \mathrm{GFI}=0.895\right.$, $\mathrm{TLI}=0.890, \mathrm{CFI}=0.880, \mathrm{IFI}=0.900, \mathrm{RMSEA}=0.082, \mathrm{SRMR}$ $=0.082$ ). Also, nine out of 12 hypotheses were supported by the data. All hypotheses (H1, H2, H3, H4, H6, H7, H9, H11, and $\mathrm{H} 12$ ) representing the relationship among the main constructs (PE, EE, SI, FC, RTC, PHT, Q, LQE, and PSR) to intention to use M-Health were supported in this study. The hypotheses that were not supported were H4: FC to intention, H5: RTC to intention, and H10: CC to intention. FC, RTC, and CCs did not significantly predict intention to use MHealth $(0.07,0.06$, and 0.12 , not significant [n.s.]); therefore, $\mathrm{H} 4$, H5, and $\mathrm{H} 10$ were not supported.

As shown in - Table 4, PE positively predicted intention to use M-Health $(0.37, p<0.001)$; therefore, H1 was supported. Second, EE significantly predicted intention $(0.07, p<0.05)$; therefore, H2 was supported. Third, SI significantly predicted intention $(-0.03,0<0.05)$; therefore, H3 was supported. Fourth, FC did not predict intention $(0.08$, n.s.). Fifth, the RTC did not directly predict intention $(-0.13$, n.s.), rejecting $\mathrm{H} 5$; however, RCT predicted intention through PE $(-0.44$, $p<0.05)$, supporting H6. PHT directly predicted intention $(0.18, p<0.05)$ and indirectly through PE $(0.37, p<0.01)$; therefore, $\mathrm{H} 7$ and $\mathrm{H} 8$ were supported. M-Health $\mathrm{Q}$ significantly predicts intention $(0.39, p<0.001)$; therefore, H9 was supported. CC did not predict intention $(-0.03$, n.s.), thus H10 was rejected. LQE significantly predicted intention (0.12, $p<0.01)$, supporting H11. Finally, PSR negatively 
Table 4 Hypotheses testing results

\begin{tabular}{|l|l|l|}
\hline Hypothesis & T statistics & Supported? \\
\hline H1: PE has a positive effect on patient intentions to use M-Health. & $4.78^{\text {a }}$ & Y \\
\hline H2: EE has a negative effect on patient intentions to use M-Health. & $1.88^{\text {b }}$ & Y \\
\hline H3: SI has a positive effect on patient intentions to use M-Health. & $2.78^{\text {c }}$ & Y \\
\hline H4: FCs have a positive effect on patient intentions to use M-Health. & 0.07 & $\mathrm{~N}$ \\
\hline H5: RTC has a negative effect on patient intentions to use M-Health. & 0.06 & $\mathrm{~N}$ \\
\hline H6: RTC has a negative effect on the PE of M-Health. & $1.91^{\mathrm{b}}$ & $\mathrm{Y}$ \\
\hline H7: PHT has a positive effect on patient intentions to use M-Health. & $2.09^{\mathrm{b}}$ & $\mathrm{Y}$ \\
\hline H8: PHT has a positive effect on PE of M-Health. & $2.62^{\mathrm{c}}$ & $\mathrm{Y}$ \\
\hline H9: Q has a positive effect on patient intentions to use M-Health. & $5.33^{\mathrm{a}}$ & $\mathrm{Y}$ \\
\hline H10: CC have a negative effect on patient intentions to use M-Health. & 0.12 & $\mathrm{~N}$ \\
\hline H11: LQE has a positive effect on patient intentions to use M-Health. & $2.59^{\mathrm{c}}$ & $\mathrm{Y}$ \\
\hline H12: PSR have a negative effect on patient intentions to use M-Health. & $2.16^{\mathrm{b}}$ & $\mathrm{Y}$ \\
\hline
\end{tabular}

Abbreviations: CC, cost concern; EE, effort expectancy; FC, facilitating condition; LQE, life quality expectancy; M-Health, mobile health; PE, performance expectancy; PHT, perceived health threat; PSR, privacy and security risk; Q, M-Health app quality; RTC, resistance to change; SI, social influence.

asignificant at 0.001 .

bSignificant at 0.05 .

'Significant at 0.01 .

predicted intention $(-0.09, p<0.05)$, and therefore $\mathrm{H} 12$ was supported.

\section{Discussion}

Using mobile ICT to provide health care services is a fast growing practice in numerous countries, both developed and developing ones. Major drivers of this phenomenon include the widespread use of more powerful smartphones and the availability of a convenient number of M-Health apps the users can easily download and use for different categories of health care services. Despite the potential benefits of MHealth to the different parties in health care (e.g., patients, service providers, health care organizations) and despite the availability of M-Health apps that satisfy the needs of all kind of patients, a wide implementation, success, and use of MHealth totally depend on users' acceptance of this technology and its benefits.

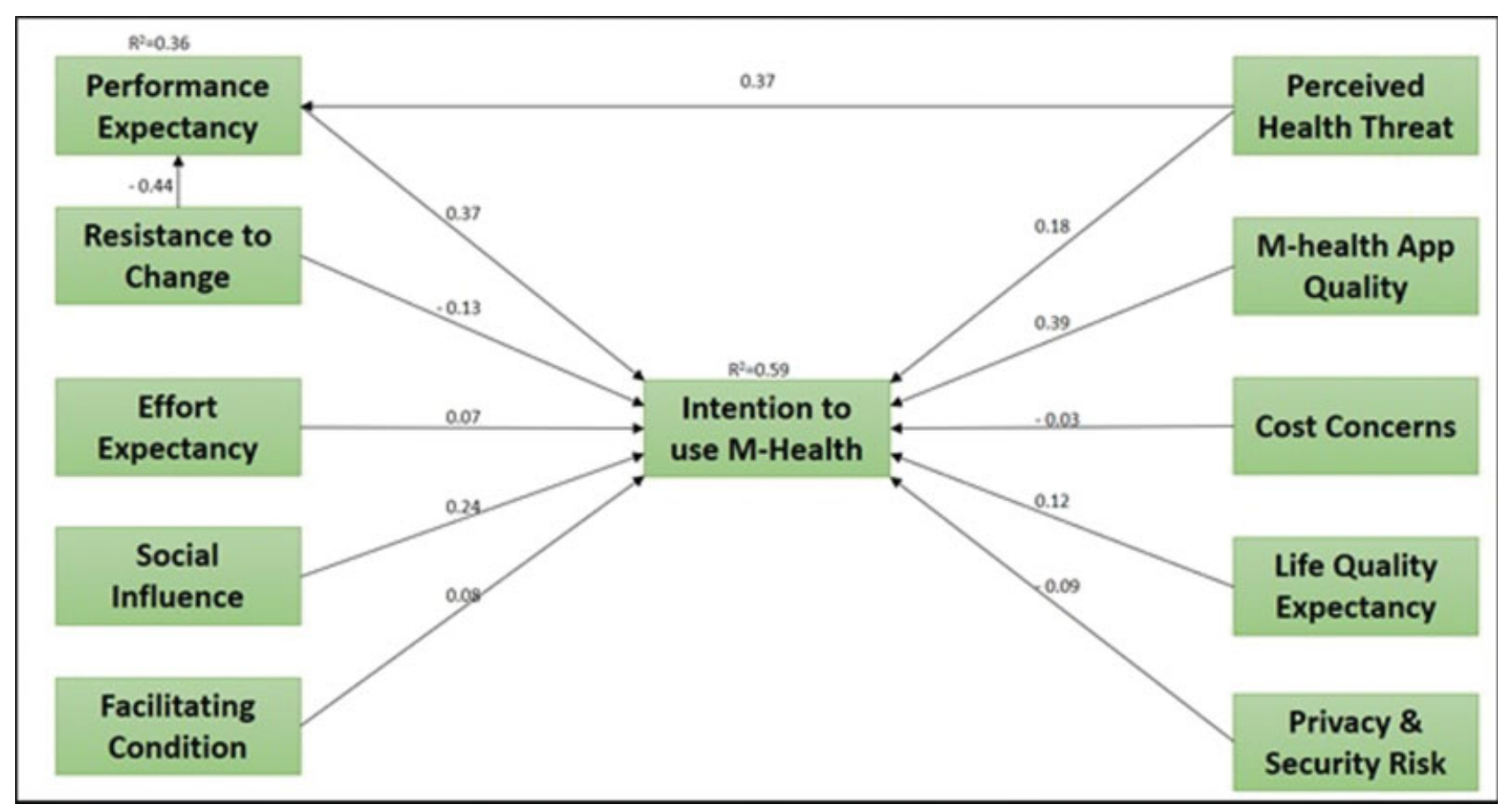

Fig. 2 Structural model results. 
This study is based on theories of technology acceptance and health behavior. We developed a unified model to explain patients' intention to adopt M-Health behavior in developing countries. The unified model integrated UTAUT, DFM, and HBM models. While UTAUT focuses on general technology acceptance issues, the integration of DFM allows for considering the negative factors which affect the intention to adopt M-Health. Furthermore, to overcome the limitations of the previous two models of being general TAMs, the HBM allows for contextualizing the model in health care settings.

Results from the data analysis provide support for our proposed theoretical model. Out of the 12 hypotheses we proposed in the model, nine were supported, and only three were statistically insignificant. Overall, the model managed to explain 0.59 of the variances in the dependent variable, intention to use M-Health.

As illustrated in the SEM results, all UTAUT model constructs were supported except for FC. In accordance with previous literature, PE (H1) emerged as the strongest determinant of intention to use M-Health among the UTAUT factors. ${ }^{15,125,126}$ In fact, PE is the second strongest determinant in the model, behind only M-Health Q. PE is related to users' perception that M-Health apps will improve their personal health care management and consequently improve their quality of life. This indicates that the ability of M-Health apps to provide useful functionalities and features will positively contribute to users' adoption of these apps. Nevertheless, unlike mobile apps in different contexts which provide the same functionalities for all users, patients' requirements differ based on the patient's condition or disease. Therefore, it is crucial for M-Health apps to be customizable to satisfy the needs of different categories of patients. More importantly, special care should be taken for patients with disabilities. Based on this finding, M-Health app developers and designers may consider the following design considerations in relation to PE for effective M-Health apps: (1) M-Health apps should enable greater control of symptoms by "self-care," (2) M-Health apps should enhance patient-doctor communication outcomes via feedback, which should be organized in a way information being utilized for improvement in health care (e.g., counts and graphs), (3) M-Health developers and designers should carefully estimate the time that will be spent to use the app services. The patients' willingness to invest time positively related to the potential benefit gained and should be no longer than any other alternatives, (4) M-Health app services should be organized in a way (e.g., tree and hierarchy) to provide patients with a list of tasks to perform for a predefined goal. Also, screens should be designed to match the task processes appropriately to assist patients in completing the tasks accurately and in a timely manner.

The effect of EE (H2) is also supported, which indicates that for wider adoption of M-Health apps in developing countries, users must perceive the technology as being simple, easy to learn, and convenient for accomplishing necessary tasks. Dwivedi et $\mathrm{al}^{40}$ argued that in the context of M-Health EE has to do with the degree of ease associated with the remote and self-use of the information system. Therefore, for wider adoption of M-Health apps, designers should provide the patients with ownership of the system with minimal need for organizational support. M-Health developers and designers may use the following design considerations as a guideline to achieve this objective: (1) M-Health apps should be compatible with patients' skills, preferences and desires, and suited to age groups. Complexity should be avoided and simplicity should be sought in the design of the application. (2) Patients would appreciate increased standardization across different forms, reports, and models of the application. (3) The language and instructions for browsing should be easy to understand with appropriate font type, style, and color. It should be a bilingual interface (Arabic and English). (4) M-Health apps should be more relaxing, enjoyable, and engaging than any other alternatives. (5) Touch screen interaction used to be based simply on the idea of "point to select." Multitouch gestures and automatic speech recognition may be embedded in the app design. Images and data visualization help users of many ages and with differing mental capacities to more easily digest information.

SI (H3) is also supported. SI is a major determinant when it comes to personal health decisions and the use of technology. It is argued in the literature that patients are frequently affected by the surrounding SI when it comes to making health decisions such as seeing a doctor or undergoing a surgery. ${ }^{27,127-129}$ In terms of technology usage, SI is also considered a major determinant of technology adoption and use. $^{28,32,130,131}$ Campbell et al ${ }^{130}$ argued that in the context of mobile communication technology, users' adoption and use is influenced by other people within their networked environment who use the same technology. Thus, the existence of mass users of M-health technology would affect others' decisions to use the technology due to SI. Some design considerations may include: (1) developers and designers should focus on selecting appropriate technologies that embrace clean design, and effective communication of the technology's capabilities through product brochures, live demonstrations, online forums for sharing best practices, and success stories among patients. (2) The data sharing policy needs to be carefully considered in the application design. Sharing of health-behavior information with others (e.g., lessons learned, patients' experience, and best practices) within the application and on social networks should be clearly developed. Such social features are found in commercial applications (e.g., Fitbit, Nike+, Jawbone UP). (3) A "sense of presence" is a key design component of social interaction where patients may forget that they are communicating through a system and feel like they are meeting faceto-face.

FC (H4) is the only factor of the UTAUT model that is rejected. Results show that the effect of FC on users' intention to use M-Health is insignificant. This result is consistent with previous studies. ${ }^{27,28}$ FCs are related to the existence of organizational and technical infrastructure that supports $\mathrm{M}-$ Health apps and services. The rejection of $\mathrm{H} 4$, in the light of acceptance of $\mathrm{H} 1$ to $\mathrm{H} 3$, could indicate that users are 
willing to use M-Health technologies regardless of any organizational support as long as the app provides satisfactory performance and easy-to-use functionalities. The availability of several M-Health apps for personal health management enables users to exhibit self-control of their health data. Users nowadays can download M-Health apps that best serve their health care needs, such as monitoring vital signs, medication reminders, and a healthy lifestyle, regardless of the existence of specific health care organizations to support these apps. Furthermore, taking into consideration that the majority of the study's subjects were millennials who are accustomed to using different categories of mobile apps, FC would be less important for this specific population to use M-Health technology. However, designers and developers may consider the following guidelines in relation to FC: (1) the availability of M-Health app on a wide range of platforms, (2) interoperability of M-Health with EHR and other existing IT tools, and (3) providing patients with manuals, online assistance, technical support, and training sessions. Help desk and online messenger support may be useful too.

H5 and H6 in our model are based on the DFM, which focuses on factors that inhibit technology usage, specifically RTC. We hypothesized a negative effect of change resistance on intention to use M-Health (H5) and on PE (H6). Our results provide support for $\mathrm{H} 6$ but fail to support $\mathrm{H} 5$. This means that users, in general, are not hesitant to change when it comes to using M-Health. However, the support of H6 indicates that users' intention to use M-Health apps has more to do with the apps' performance. That is, when users manage to find MHealth app that satisfies and meets their expectations, they would be willing to accept the change. RTC is independent of but may coexist with enablers such as PE. The indirect effect suggests that inhibitors tend to influence (or "bias") adopters' perception of enablers in a negative manner. In other words, the study confirmed that RTC indeed had a biasing effect on patients' perception of PE of the M-Health app. Its indirect negative effect on behavioral intention through the mediation of PE was consistent with the previous studies on patient acceptance of HIS. ${ }^{132}$ Although M-Health apps are expected to improve quality of care, reduce medical errors, and improve medical service delivery, the findings suggest that many patients do not perceive these benefits via their smartphones and technology resistance hinders the perceptions of system performance. This is because M-Health systems are essentially workflow systems that automate, streamline, and restructure the way patients interact with doctors, schedule an appointment, and monitor health status. Besides, they force patients to abandon their traditional practice of visiting hospitals, interacting with doctors, getting treatment and tests done, instead they require entering data into a phone through a complex series of screens and numerous checks. This reflected a natural tendency for some patients to prefer to continue with the traditional way of health care management over switching to use the new smartphone technology. To alleviate this, developers and designers may consider: (1) the use of "social presence" to enhance the interaction between patients and doctors,
(2) using artificial intelligence (AI) techniques such as Natural Language Processing (NLP), voice recognition, speech recognition, and face recognition to provide advanced services looking as operated in a real environment, (3) using avatars, graphical visualizations, and animations to increase the awareness of different parties, and (4) using contextual cues in facilitating the exchange of data and information in a communication channels.

H7 and H8 in our model are based on the HBM, which suggests that when users are more aware of the health threats they might face and their consequences, they will be more willing to use M-Health. The support of $\mathrm{H} 7$, which hypothesizes a positive relationship between health threats and intention to use M-Health, as well as H8, which hypothesizes a positive relationship between health threats and PE, indicates that when users are more aware of the potential health threats they have, they will be more willing to use MHealth perhaps to manage these threats and be able to resolve them once they occur. Even more, the support of $\mathrm{H} 8$ indicates that users will evaluate their perceived PE of MHealth in accordance with the health threat they are concerned about. This means that patients will adopt M-Health apps which provide useful information that helps them deal with their health threats. The acceptance of $\mathrm{H} 6$ and $\mathrm{H} 8$ highlights the importance of M-Health apps' performance from the point view of the patients. This suggests that patients evaluate M-Health apps through the apps' ability to provide useful information which assists patients in dealing with their health threats. Moreover, well-designed apps that meet the patients' expectations would overcome their RTC and use the apps. Further, the indirect effect of PHT on usage intention through PE was significant. That is, when patients perceive their health to be at risk and susceptible to diseases, they assess and evaluate the benefits and barriers of utilizing the M-Health services to alleviate the risk. In other words, they examine how they can use these services and which service is more beneficial to overcome the risk. If benefits perceived, they would use the M-Health services.

In addition to the factors adopted from UTAUT, DFM, and HBM, our model included four factors based on the qualitative data we gathered for the purpose of this research. The first factor is M-Health Q(H9), which refers to users' positive evaluation of the M-Health app features. Our results provide support for H9, which indicates that when an M-Health app includes high-quality features in terms of technical adequacy, content, and appearance, users would be more willing to use the app. In fact, M-Health Q appeared to be the strongest determinant of users' intention to use M-Health. This finding is of utmost importance to app designers and developers. That is, with the availability of many M-Health apps for users to choose from, the apps with higher quality from the users' perspective would be the ones users are willing to use and trust for their personal health information. For effective MHealth design, developers and designers may (1) avoid overwhelming patients with unnecessary or irrelevant data. The value of the apps derives from an intelligent, insightful presentation of data, (2) use appropriate communication format to facilitate interactions with doctors (for 
example, short message service [SMS], multimedia messaging service [MMS], interactive voice response [IVR], video, voice, general packet radio service [GPRS]), (3) use appropriate feedback forms such as counts, graphs, stylized representations, and narrative information, (4) given the limited screen size of mobile phones, use submenus, provide a feedback about current place in the app, use appropriate font color and background, and balance text size and amount of text on screen, (5) while reading a text, enable the patients to change the font size, font type, and orientation of the text, (6) balance the design requirements such as providing back options, consistency of command names, feedback to users about where they are in the application, and organization of menus, (7) use automatic adaptation of a general mobile application across terminals. This includes adapting the size of the text dependent on the amount of content of the screen, and the use of shortcuts.

The second factor is CC (H10), which was rejected. Our results show that users do not seem to be concerned about $\mathrm{M}$-Health cost. Taking into consideration that the majority of M-Health apps are free, and many of them are currently standard on most mobile phone brands, it comes as no surprise that users have little to no concern regarding $\mathrm{M}$-Health cost. These findings could also be explained by the fact that mobile phone prices are relatively attainable and the cost of mobile and data subscription in Jordan is significantly low. ${ }^{13}$ However, designers and developers should be aware of the wide range of costs associated with developing, deploying, and maintaining M-Health apps. Some are onetime costs, while others must be budgeted annually (or at other regular intervals). They should also find sustainable and cost-effective models.

The third factor is LQE (H11), which was supported. LQE has to do with users' perception that M-Health improves their personal health data management, independence, and personal lifestyle. The support of $\mathrm{H} 11$ indicates that users are taking matters into their own hands to better manage their own health without the frequent need for health care providers. Through the use of M-Health, users can personally monitor their vital signs, search for medical information, and record personal health data. Furthermore, with the increased awareness of the need for a healthy living style among people of different ages, ${ }^{133} \mathrm{M}$-Health can provide means to achieve this objective in areas such as exercise and healthy nutrition. Based on this finding, M-Health developers and designers may use the following design considerations: (1) the apps should automatically collect data about health-related behaviors, provide users with feedback about their life style, and help them track progress toward preset goals, (2) the apps should allow the customization of electronic prompts and reminders according to end users' needs and expectations, (3) the apps should automatically change screens backgrounds and colors based on target patients and their behavior, (4) the apps should collect and store data, often in real time, keeping users informed about what is going on, through appropriate feedback within reasonable time, (5) the apps should be integrated into the patterns of people's daily lives and make minimal external demands, (6) the apps should use AI methods to improve user interaction with the app such as speech detection and NLP. AI can evaluate the environmental context of the user (e.g., determine whether it is day or night; location based on proximity detection). AI can also assist with other basic, but important, "behind the scene" functions such as preserving battery life of mobile technologies, again by being aware of the environment (turning some functions off), (7) the apps should use graphs that display users' tracked activities over time, typically using line or bar charts, and support reflection on the possible relationships among different types of activities and metrics.

The fourth and final factor addresses PSR (H12). Our results show that users perceive a negative relationship between PSRs on one hand and intention to use M-Health on the other hand. Health information is considered purely personal, and people do not favor sharing it with anyone else. Mobile users are generally concerned with how their data on mobile devices and mobile networks are kept safe from any unauthorized access. Security and privacy concerns are even higher when they are related to personal health information. When users depend on an M-Health app or service to record and save their data, they have legitimate concerns about who has access to these data and how the service sponsors use it. While developed countries have sophisticated and strict laws and regulations that govern the storage, use, and distribution of personal health data (such as the Health Insurance Portability and Accountability Act [HIPAA] in the United States and the General Data Protection Regulation [GDPR] in Europe), developing countries often lack such regulations. Consequently, M-Health users in developing countries are often using M-Health services at their own risk, which makes them prone to data breaches and misuse by unknown parties. This calls for the need for adequate regulations that accommodate the users' need for M-Health while protecting users from malicious services. Some design considerations may include (1) protecting the apps with strong firewalls, complex passwords, regular security reviews, and software updates, (2) role-based access should be integrated into the system infrastructure so that when users logged on, they would only see screens related to their own role, (3) maintaining security by requiring different user code and password entries at each level instead of a single password access. Biometric identification such as finger print or face recognition may be used. (4) Automated generation of encrypted backup files at regular intervals, (5) the ability to remotely lock and wipe data when devices are lost. For example, if patients lose their smartphone, they can log into the iCloud from another device and erase the phone's information remotely. (6) The system may undergo a third-party security test. (7) To minimize risks to the patient's privacy, for sensed data, it might be better to only keep high-level inferences and not the raw data themselves, to avoid unintended exposure of sensitive information.

\section{Implications for Theory}

This research contributes to the existing literature of HIS and provides several implications for theory. First, this study 
provides better understanding of how different factors may affect the adoption and the intention to use personal HIS artifacts in general and M-Health apps in particular in the context of developing countries. Second, it is designed based on relevant theories and proposes a unified technology adoption model to overcome the limitations of the traditional adoption theories in investigating the intention to use $\mathrm{M}$-Health apps. Hence, our study has examined the different factors that may affect the intention to use M-Health, drawing on the UTAUT theory and extending its lenses using the HBM and DFM. Given the complexity of M-Health apps and the numerous factors that may affect their use, this study bridges the gap of previous studies that used a limited number of constructs and applied UTAUT, HBM, and DFM individually. ${ }^{51,134,135}$ Our article provides a wider understanding of the different factors that may affect the intention to use M-Health. To our knowledge, this study is one of the first studies to empirically explore the effects and the impact of different determinants on M-Health adoption in developing countries from the perspective of UTAUT, HBM, and DFM together.

Third, existing research in information systems has mainly explored the overall beliefs about system usage, antecedents of system satisfaction, and other perceptions that enable information systems success and create a positive attitude that encourages use. However, there has been less attention given to what may hinder intention to use the information system. This study adds to the HIS body of knowledge by using the DFM that considers both positive and negative factors to examine users' M-Health intention to use. Such a contribution will enrich the existing HIS literature, particularly the research associated with telehealth and M-Health applications and technologies at the individual level. In addition, this study contributes to the existing literature of M-Health by identifying how technological, social, and functional factors are associated with health digital applications and services use and success. Fourth, based on qualitative data we gathered, we identified four additional factors which influence the intention to use M-health. Two of these factors (quality and security) were significant, which indicates that the current TAMs should be extended to include more factors mainly when applied to health care and M-Health apps contexts.

\section{Implications for Practice}

M-Health apps have drawn the attention of health care providers as a modality for delivering services in a more cost-effective way and reducing geographic and distance barriers. There is increased attention from health care providers and decision makers to leverage $\mathrm{M}$-Health to provide service for underserved communities and individuals. ${ }^{136-138}$ Nonetheless, with hundreds of M-Health apps available in the digital market, patients, caregivers, and health care providers need guidance on identifying apps that provide good information, provide good service, and are easy to use, safe, secure, and effective.

Our research can help health care providers and M-Health developers and designers to better understand the strengths and weaknesses of existing M-Health apps from the users' perceptions, which will yield a better understanding of an individual's intention of using such apps and thus better manage their health and conditions. With the widespread availability of mobile technologies and services and the growing demand for M-Health apps, our research can help guide the development of the next generation of M-Health apps with a focus on the needs of patients in developing countries. Following a patient-centered design, we have uncovered a set of facilitators and barriers for adoption of M-Health services from patients' perspective, we have identified the patients' functional requirements, needs, and expectations from M-Health apps, we have also identified the importance of each adoption factor and which one is more significant than others, and we have finally proposed a set of design considerations and criteria that acts as a guideline for effective implementation of M-Health apps.

We draw multiple managerial and practical implications from this study. First, M-Health apps' qualities and functionalities play a valuable role in patients' intention to use the apps. Hence, developers and designers should pay attention to what type of functions they provide in their applications and how these functions could be customized to satisfy the needs of different' categories of patients. Second, given the sensitivity of an individual's health and overall well-being, M-Health providers and developers should take into consideration how individuals perceive health threats and how such threats may influence their intention to use M-Health apps. Third, our results show the impact of SI on the use of M-Health. SI has to do with the behavior change that a person causes in another person. Thus, it is important for M-Health apps to influence their users' behavior and life style to affect others and encourage them to adopt the technology. This could be accomplished through careful design of the apps to have greater impact on patients' health which could be observed by others. Also, developers could identify users who value health apps and incorporate their feedback to enhance future releases.

Fourth, given the sensitive nature of the data that M-Health apps store and process, security and privacy greatly affect how users perceive M-Health apps and subsequently affect their intention to use M-Health. Developers should pay close attention to the type of security and privacy measures they add to their health apps and inform the users about these measures to assure them that their data will remain secure and confidential. If the apps are not fully developed or request additional unneeded information from the user, this will negatively affect users' perception of how their medical and health private information is being handled and thus affect the intention to use M-Health apps. There is a crucial need for developers to maintain a balance between providing more functions and keeping the data safe and secure. Also, it is important for M-Health developers and designers to make sure that their apps conform to local and international laws and regulations that govern how personal health data are collected, processed, and stored. 
Fifth, our results indicate that $\mathrm{M}$-Health cost has no significant impact on the intention to use M-Health apps, which has very interesting implications in practice. We found that there are other factors that individuals care about more in regard to the intention to use $\mathrm{M}$-Health apps, but the cost of the health app is not one of them. The literature on mobile apps shows that users are sensitive to the cost of the apps and how this may affect downloading apps, adopting them, and using them. In the context of health care, users are generally less concerned about cost because of the perceived positive effects of M-Health apps on their health and wellbeing. Our research highlights practical implications to support the development and design of health IT with the goal of providing more effective and sustainable health care delivery and services especially in developing countries.

\section{Limitations and Directions for Future}

This study has various limitations. First, we surveyed only Jordanians as a case of a developing country, which may raise concern about the generalizability of the findings to other developing countries. Future research should give more attention to collect data from various developing countries. Second, we surveyed mostly younger patients in Jordan. Future research could investigate M-Health adoption among another age group, such as the elderly, and compare the results. Third, the research model was tested from the patients' perspective but not from the perspective of medical professionals. Future research could investigate the factors influencing the adoption by medical professionals and compare the results. Fourth, we did not investigate the moderating effects of age, experience, culture, and gender, which are worthy of future exploration.

\section{Conclusion}

The objective of this research is to provide a theoretical model to explain the determinants of M-Health adoption in developing countries' settings from patients' perspective. The theoretical foundation of this research is based on the UTAUT, DFM, and HBM. In addition, based on data gathered via qualitative interviews, new factors were added to the theoretical model: M-Health Q CC, LQE, and PSRs. To test our theoretical model, a survey instrument was developed. The setting of this study is a developing country (Jordan), and a convenience student sample was used to collect data. Partial least square SEM was used to test the data using the SmartPLS software.

The findings showed that PE, EE, SI, PHT, M-Health Q, and LQE have a direct positive effect on the patient's intention to use M-Health. The findings also showed that PSRs have a direct negative effect on the patient's intention to use M-Health. However, RTC was found to have an indirect negative effect on their intention through the PE. Among the influencing factors, M-Health $\mathrm{Q}$ was found to be the strongest predictor for the intention. The findings have several theoretical and practical implications for the health care industry, government, policy makers, and technology developers.

\section{Clinical Relevance Statement}

Please check implications.

\section{Multiple Choice Questions}

1. What is the strongest predictor of M-health adoption?
a. Performance expectancy.
b. Effort expectancy.
c. M-Health app quality.
d. Life quality expectancy.

Correct Answer: The correct answer is c. As described in the discussion, in accordance with previous literature, performance expectancy (PE) emerged as the strongest determinant of intention to use M-Health among the UTAUT factors. In fact, PE is the second strongest determinant in the model, behind only M-Health app quality in our study.

2. This study is grounded on all the following theories except a. UTAUT.

b. DFM.

c. HBM.

d. TTF.

Correct Answer: The correct answer is d. As discussed in the background, this research provides a model that explains the adoption behavior of patients in using MHealth based on various relevant theories such as the unified theory of acceptance and use of technology (UTAUT), the dual-factor model (DFM), and the health belief model (HBM).

\section{Protection of Human and Animal Subjects}

This study was reviewed and approved by Jordan University of Science and Technology Institutional Review Board.

Conflict of Interest

None declared.

\section{References}

1 Kahn JG, Yang JS, Kahn JS. 'Mobile' health needs and opportunities in developing countries. Health Aff (Millwood) 2010;29 (02):252-258

2 Sam S. Towards an empowerment framework for evaluating mobile phone use and impact in developing countries. Telemat Inform 2017;34(01):359-369

3 Househ M, Borycki M, Kushniruk W, Alofaysan S. mHealth: a passing fad or here to stay? In: Rodrigues J, de la Torre Díez I, Sainz B, eds. Telemedicine and e-Health Services, Policies, and Applications: Advancements and Developments. Hershey, PA: IGI Global; 2012:151-178

4 Economist. Mobile health apps are becoming more capable and potentially rather useful. Available at: http://www.economist. com/news/business/21694523-mobile-health-apps-are-becoming-more-capable-and-potentially-rather-useful-thingsare-looking. Published 2016. Accessed January 2, 2019

5 Barton. Mobile Health Technologies and Global Markets. BCC Publishing; 2017. Available at: https://www.bccresearch.com/ 
market-research/healthcare/mobile-health-technologies-report.html. Accessed December 12, 2018

6 Krebs P, Duncan DT. Health app use among US mobile phone owners: a national survey. JMIR Mhealth Uhealth 2015;3(04): e101

7 Aitken M, Gauntlett C. Patient Apps for Improved Healthcare: from Novelty to Mainstream. Parsippany, NJ: IMS Institute for Healthcare Informatics; 2013

$8 \mathrm{Yu}$ P, Wu MX, Yu H, Xiao G. The challenges for the adoption of $\mathrm{m}-$ health. Paper presented at: the 2006 IEEE International Conference on Service Operations and Logistics, and Informatics; July 10, 2016, Beijing, China

9 Luxton D, McCann R, Bush N, Mishkind M, Reger G. mHealth for mental health: Integrating smartphone technology in behavioral healthcare. Prof Psychol Res Pr 2011;42(06):505-512

10 ITU. Statistics. Available at: https://www.itu.int/en/ITU-D/Statistics/Pages/stat/default.aspx2018. Accessed September 3, 2019

11 Gallagher J, O'Donoghue J, Car J. Managing immune diseases in the smartphone era: how have apps impacted disease management and their future? Expert Rev Clin Immunol 2015;11(04): 431-433

12 Chib A, van Velthoven MH, Car J. mHealth adoption in lowresource environments: a review of the use of mobile healthcare in developing countries. JHealth Commun 2015;20(01): 4-34

13 Alsharo M. Attitudes towards cloud computing adoption in emerging economies. Int J Cloud Appl Comput 2017;7(03):44-58

14 Jordan's Telecommunication Regularity Commission (2019). Available at: https://trc.gov.jo/Pages/viewpage?pageID=215. Accessed September 3, 2019

15 Venkatesh M, Davis D. User acceptance of information technology: toward a unified view. Manage Inf Syst Q 2003;27(03): $425-478$

16 Cenfetelli R. Inhibitors and enablers as dual factor concepts in technology usage. J Assoc Inf Syst 2004;5(11):472-492

17 Cenfetelli R, Benbasat I, Al-Natour S. Addressing the what and how of online services: positioning supporting-services functionality and service quality for business-to-consumer success. Inf Syst Res 2008;19(02):161-181

18 Janz NK, Becker MH. The health belief model: a decade later. Health Educ Q 1984;11(01):1-47

19 Davis F. Perceived usefulness, perceived ease of use, and user acceptance of information technology. Manage Inf Syst Q 1989; 13(03):319-340

20 Rogers M. Diffusion of Innovations.5th ed. New York, NY: Free Press; 2003

21 Ajzen I, Fishbein M. Understanding Attitudes and Predicting Social Behaviour. Pbk ed. Englewood Cliffs, NJ: Prentice Hall; 1980

22 Ajzen I. The theory of planned behavior. Organ Behav Hum Decis Process 1991;50(02):179-211

23 Rahimi B, Nadri H, Lotfnezhad Afshar H, Timpka T. A systematic review of the technology acceptance model in health informatics. Appl Clin Inform 2018;9(03):604-634

24 Zhou T. Examining location based services usage from the perspectives of unified theory of acceptance and use of technology and privacy risk. JElectron Commerce Res 2012;13(02): 135-144

25 Kijsanayotin B, Pannarunothai S, Speedie SM. Factors influencing health information technology adoption in Thailand's community health centers: applying the UTAUT model. Int J Med Inform 2009;78(06):404-416

26 Alzahrani M, Goodwin R. Towards a UTAUT-based model for the study of E-government citizen acceptance in Saudi Arabia. Int. J. Econ. Manage. Sci 2012;6(04):109-115

27 Hoque R, Sorwar G. Understanding factors influencing the adoption of mHealth by the elderly: an extension of the UTAUT model. Int J Med Inform 2017;101:75-84
28 Quaosar GMAA, Hoque MR, Bao Y. Investigating factors affecting elderly's intention to use m-health services: an empirical study. Telemed J E Health 2018;24(04):309-314

29 Davis F, Bagozzi R, Warshaw P. Extrinsic and intrinsic motivation to use computers in the workplace. JAppl Soc Psychol 1992;22 (14):1111-1132

30 Jovanov E. Wireless technology and system integration in body area networks for $\mathrm{m}$-health applications. Paper presented at: the 27th IEEE Annual International Conference of the Engineering in Medicine and Biology Society; September 1, 2006; Shanghai, China

31 Nkosi M, Mekuria F. Cloud computing for enhanced mobile health applications. Paper presented at: the 2010 IEEE Second International Conference on Cloud Computing Technology and Science (CloudCom); November 30, 2010; Indiana, United States

32 Hoque MR. An empirical study of mHealth adoption in a developing country: the moderating effect of gender concern. BMC Med Inform Decis Mak 2016;16(01):51

33 Onaolapo S, Oyewole O. Performance expectancy, effort expectancy, and facilitating conditions as factors influencing smart phones use for mobile learning by postgraduate students of the University of Ibadan, Nigeria. Interdisciplinary Journal of e-Skills and Lifelong Learning 2018;14:095-115

34 Pai F, Huang K. Applying the Technology Acceptance Model to the introduction of healthcare information systems. Technol Forecast Soc Change 2011;78(04):650-660

35 Carlsson B. Internationalization of innovation systems: a survey of the literature. Res Policy 2006;35(01):56-67

36 Taylor S, Todd P. Understanding information technology usage: a test of competing models. Inf Syst Res 1995;6(02):144-176

37 Nadri H, Rahimi B, Lotfnezhad Afshar H, Samadbeik M, Garavand A. Factors affecting acceptance of hospital information systems based on extended technology acceptance model: a case study in three paraclinical departments. Appl Clin Inform 2018;9(02): 238-247

38 Sun Y, Wang N, Guo X, Peng Z. Understanding the acceptance of mobile health services: a comparison and integration of alternative models. JElectron Commerce Res 2013;14(02): 183-200

39 Boontarig W, Chutimaskul W, Chongsuphajaisiddhi V, Papasratorn B. Factors influencing the Thai elderly intention to use smartphone for e-Health services. Paper presented at: the IEEE Symposium on Humanities, Science and Engineering Research; 24-27 June 2012; Kuala Lumpur, Malaysia

40 Dwivedi Y, Shareef M, Simintiras A, Lal B, Weerakkody V. A generalised adoption model for services: a cross-country comparison of mobile health (m-health). Gov Inf Q 2016;33(01): 174-187

41 Wills MJ, El-Gayar OF, Bennett D. Examining healthcare professionals'acceptance of electronic medical records using UTAUT. Issues Inf Syst 2008;9(02):396-401

42 Ahadzadeh AS, Pahlevan Sharif S, Ong FS, Khong KW. Integrating health belief model and technology acceptance model: an investigation of health-related internet use. J Med Internet Res 2015; 17(02): 45

43 Zhang X, Han X, Dang Y, Meng F, Guo X, Lin J. User acceptance of mobile health services from users' perspectives: the role of selfefficacy and response-efficacy in technology acceptance. Inform Health Soc Care 2017;42(02):194-206

44 Rogers M. Diffusion of Innovations. 4th ed. Boston, MA: Free Press; 1995

45 Lapointe L, Rivard S. A multilevel model of resistance to information technology implementation. MIS Q 2005;29(03): 461-491

46 Freudenheim M. Many hospitals resist computerized patient care. New York Times. Available at: https://www.nytimes.com/2004/ 04/06/business/many-hospitals-resist-computerized-patientcare.html. Published April 6, 2004. Accessed September 3, 2019 
47 Bhattacherjee A, Hikmet N. Reconceptualizing organizational support and itseffect on information technology usage: evidence from the health care sector.J Comput Inf Syst 2008;48(04):69-76

48 Laumer S, Eckhardt A. Why do people reject technologies: a review of user resistance theories. In: Dwivedi YK, Wade MR, Scheneberger SL, eds. Information Systems Theory: Explaining and Predicting Our Digital Society, Vol. 1. New York, NY: Springer; 2012:63-86

49 Samhan B, Joshi D. Understanding electronic health records resistance: a revealed causal mapping approach. Int J Electron Healthc 2017;9(02):100-128

50 Özdemir-Güngör D, Camgöz-Akdağ H. Examining the effects of technology anxiety and resistance to change on the acceptance of breast tumor registry system: evidence from Turkey. Technol Soc 2018;54:66-73

51 Guo X, Sun Y, Wang N, Peng Z, Yan Z. The dark side of elderly acceptance of preventive mobile health services in China. Electron Mark 2012;23(01):49-61

52 Holden RJ, Karsh BT. The technology acceptance model: its past and its future in health care. JBiomed Inform 2010;43(01): 159-172

53 Yuan S, Ma W, Kanthawala S, Peng W. Keep using my health apps: discover users' perception of health and fitness apps with the UTAUT2 model. Telemed J E Health 2015;21(09):735-741

54 Rosenstock I. Historical origins of the health belief model. Health Educ Monogr 1974;2(04):328-335

55 Ahn T, Ryu S, Han I. The impact of web quality and playfulness on user acceptance of online retailing. Inf Manage 2007;44(03): 263-275

56 Calisir F, Altin Gumussoy C, Bayraktaroglu A, Karaali D. Predicting the intention to use a web-based learning system: perceived content quality, anxiety, perceived system quality, image, and the technology acceptance model. Hum Factors Ergon Manuf Serv Ind 2014;24(05):515-531

57 Srinivasan A. Alternative measures of system effectiveness: associations and implications. Manage Inf Syst Q 1985;9(03): 243-253

58 Wang Y, Liao Y. The conceptualization and measurement of $\mathrm{m}$ commerce user satisfaction. Comput Human Behav 2007;23 (01):381-398

59 Kenteris M, Gavalas D, Economou D. Mytilene E-guide: a multiplatform mobile application tourist guide exemplar. Multimedia Tools Appl 2010;54(02):241-262

60 Floh A, Treiblmaier H. What keeps the e-banking customer loyal? A multigroup analysis of the moderating role of consumer characteristics on E-loyalty in the financial service industry. JElectron Commer Res 2006;7(02):97-110

61 Schaupp C, Fan W, Belanger F. Determining success for different website goals. Paper presented at: the 39th Annual Hawaii International Conference on System Sciences HICSS'06; January 4, 2006, Hawaii, United States

62 Sweeney M, Paruchuri K, Weingart SN. Going mobile: resident physicians' assessment of the impact of tablet computers on clinical tasks, job satisfaction, and quality of care. Appl Clin Inform 2018;9(03):588-594

63 Li Z, Jiao Y. The impact of website and offline equality on relationship quality: an empirical study on e-retailing. Paper presented at the 4th International Conference on Wireless Communications, Networking and Mobile Computing WiCOM'08; March 2, 2008; Dalian, China

64 Nelson R, Todd P, Wixom B. Antecedents of information and system quality: an empirical examination within the context of data warehousing. J Manage Inf Syst 2005;21(04):199-235

65 Wixom B, Todd P. A theoretical integration of user satisfaction and technology acceptance. Inf Syst Res 2005;16(01):85-102

66 Chang S, Tung F. An empirical investigation of students' behavioural intentions to use the online learning course websites. British J Educ Technol 2007;39(01):71-83
67 Lee J, Lee W. The relationship of e-Learner's self-regulatory efficacy and perception of e-Learning environmental quality. Comput Human Behav 2008;24(01):32-47

$68 \mathrm{Wu}$ J, Wang S. What drives mobile commerce? Inf Manage 2005; 42(05):719-729

69 Yarbrough AK, Smith TB. Technology acceptance among physicians: a new take on TAM. Med Care Res Rev 2007;64(06): 650-672

70 Aydin S, Özer G. National customer satisfaction indices: an implementation in the Turkish mobile telephone market. Mark Intell Plann 2005;23(05):486-504

71 Burnham T, Frels J, Mahajan V. Consumer switching costs: a typology, antecedents, and consequences. J Acad Mark Sci 2003; 31(02):109-126

72 Ho Cheong J, Park M. Mobile internet acceptance in Korea. Internet Res 2005;15(02):125-140

73 Dai H, Palvi P. Mobile commerce adoption in China and the United States. ACM SIGMIS Database 2009;40(04):43-61

74 Lin F, Lu I, Hsieh P. Understanding the adoption of wireless sensor network service in households. Paper presented at: the 2011 International Joint Conference on Service Sciences (IJCSS); May 25, 2011; Taipei, Taiwan

75 Steele R, Lo A, Secombe C, Wong YK. Elderly persons' perception and acceptance of using wireless sensor networks to assist healthcare. Int J Med Inform 2009;78(12):788-801

76 Schulz R. Quality of Life Technology Handbook.1st ed. Boca Raton, FL: CRC press; 2012

77 Schulz R, Beach R, Matthews T, Courtney L, Dabbs V. Designing and evaluating quality of life technologies: an interdisciplinary approach. Proc IEEE 2012;100(08):2397-2409

78 Price Waterhouse and Coopers. Emerging mhealth: paths for growth. 2013. Available at: https://www.pwc.com/gx/en/healthcare/mhealth/assets/pwc-emerging-mhealth-full.pdf. Accessed June 20, 2019

79 Research Now SSI. Are mobile health apps good for our health? 2015. Available at: https://www.hcinnovationgroup.com/population-health-management/mobile-health-mhealth/news/ 13024830/survey-doctors-and-patients-see-benefits-in-mobile-apps. Accessed June 27, 2017

80 Boult C, Green AF, Boult LB, Pacala JT, Snyder C, Leff B. Successful models of comprehensive care for older adults with chronic conditions: evidence for the Institute of Medicine's "retooling for an aging America" report. J Am Geriatr Soc 2009;57(12):2328-2337

81 Berry-Millett R, Bodenheimer TS. Care management of patients with complex health care needs. Synth Proj Res Synth Rep 2009; 19(19):52-72

82 Culley M, Herman J, Smith D, Tavakoli A. Effects of technology and connectedness on community dwelling older adults. Online J Nurs Inform 2013;17(03):1-7

83 Menon S, Sarkar S. Privacy and Big data: scalable approaches to sanitize large transactional databases for sharing. Manage Inf Syst Q 2016;40(04):963-981

84 Narayanan A, Shmatikov V. Robust de-anonymization of large sparse datasets. Paper presented at: the 2008 IEEE Symposium on Security and Privacy; May 18, 2008; California, United States

85 Pass G, Chowdhury A, Torgeson C. A picture of search. Paper presented at: the First International Conference on Scalable Information Systems. May 30, 2006; Hong Kong, 75(1):29-41

86 Westin A. Privacy and Freedom. Washington and Lee Law Review 1968;25(01):166

87 Dehzad F, Hilhorst C, de Bie C, Claassen E. Adopting health apps, what's hindering doctors and patients? Health (Irvine Calif) 2014;06(16):2204-2217

88 Tuch A, Presslaber E, Stöcklin M, Opwis K, Bargas-Avila J. The role of visual complexity and prototypicality regarding first impression of websites: working towards understanding aesthetic judgments. Int J Hum Comput Stud 2012;70(11):794-811 
$89 \mathrm{Wu}$ I, Li J, Fu C. The adoption of mobile healthcare by hospital's professionals: an integrative perspective. Decis Support Syst 2011;51(03):587-596

90 Laxman K, Krishnan S, Dhillon J. Barriers to adoption of consumer health informatics applications for self-management. Health Sci J 2015;9(5-7):1-7

91 Angst C, Agarwal R. Adoption of electronic health records in the presence of privacy concerns: the elaboration likelihood model and individual persuasion. Manage Inf Syst Q 2009;33(02): 339-370

92 Becker D. Acceptance of mobile mental health treatment applications. Paper presented at: the 6th International Conference on Current and Future Trends of Information and Communication Technologies in Healthcare (ICTH 2016). Procedia Comput Sci 2016;98:220-227

93 Ritchie J, Lewis J, Elam G. Qualitative Research Practice: a Guide for Social Science Students and Researchers. Los Angeles, CA: SAGE; 2013

94 Cho J, Lee HE, Kim SJ, Park D. Effects of body image on college students' attitudes toward diet/fitness apps on smartphones. Cyberpsychol Behav Soc Netw 2015;18(01):41-45

95 Eze C, Goh H, Ling Y, Lee H. Intention to use e-government services in Malaysia: perspective of individual users. Paper presented at: the International Conference on Informatics Engineering and Information Science; 2011; Berlin, Heidelberg; vol 252, 512-526

96 McNeil BJ, Elfrink VL, Bickford CJ, et al. Nursing information technology knowledge, skills, and preparation of student nurses, nursing faculty, and clinicians: a U.S. survey. J Nurs Educ 2003;42 (08):341-349

97 Kelley C, Lee B, Wilcox L. (2017, May). Self-tracking for mental wellness: understanding expert perspectives and student experiences. Paper presented at: Proceedings of the $2017 \mathrm{CHI}$ Conference on Human Factors in Computing Systems ACM: 629: 641; May 2017; Denver, Colorado

98 Cochran W. Sampling Techniques. 3rd ed. New York, NY: Wiley; 1977

99 Cohen J. A power primer. Psychol Bull 1992;112(01):155-159

100 Chin W. The partial least squares approach to structural equation modeling. Modern Methods for Business Research. 1998;295 (02):295-336

101 Hossain M, Prybutok V. Consumer acceptance of RFID technology: an exploratory study. IEEE Trans Eng Manage 2008;55(02):316-328

102 Product | SmartPLS. Smartpls.com. Available at: https://www. smartpls.com/. Published 2019. Accessed July 1, 2019

103 Deng Z, Hong Z, Ren C, Zhang W, Xiang F. What predicts patients' adoption intention toward mHealth services in China: empirical study. JMIR Mhealth Uhealth 2018;6(08):e172

104 Armida E. Adoption Process for VOIP: the Influence of Trust in the UTAUT Model [Phd dissertation]. Indiana, United States: Purdue University; 2008

105 Sun Q Cao H, You J. Factors influencing the adoption of mobile service in China: an integration of TAM. J Comput (Taipei) 2010;5 (05):799-806

106 Hair J, Ringle C, Sarstedt M. PLS-SEM: indeed a silver bullet. J Mark Theory Pract 2011;19(02):139-152

107 Alaiad A, Zhou L. The determinants of home healthcare robots adoption: an empirical investigation. Int J Med Inform 2014;83 (11):825-840

108 Lam T, Maguire D. Structural equation modeling: theory and applications in forest management. Int J For Res 2012; 263953:1687-9368

109 Gefen D, Straub D. A practical guide to factorial validity using PLS-Graph: tutorial and annotated example. Comm Assoc Inform Syst 2005; $16: 5$

110 Reinartz W, Haenlein M, Henseler J. An empirical comparison of the efficacy of covariance-based and variance-based SEM. Int J Res Mark 2009;26(04):332-344
111 Gefen D, Rigdon E, Straub D. Editor's comments: an update and extension to SEM guidelines for administrative and social science research. Manage Inf Syst Q 2011;35(02):3-12

112 Fornell C, Bookstein FL. Two structural equation models: LISREL and PLS applied to consumer exit-voice theory. J Mark Res 1982; 19(04):440-452

113 Cassel C, Hackl P, Westlund A. Robustness of partial least-squares method for estimating latent variable quality structures. J Appl Stat 1999;26(04):435-446

114 Cassel C, Hackl P, Westlund A. On measurement of intangible assets: a study of robustness of partial least squares. Total Qual Manage 2000;11(07):897-907

115 Kai-Uwe Brock J, Zhou Y. Organizational use of the internet. Internet Res 2005;15(01):67-87

116 Shiferaw K, Mehari E. Modeling predictors of acceptance and use of electronic medical record system in a resource limited setting: using modified UTAUT model. Informatics in Medicine Unlocked 2019. Doi: 10.1016/j.imu.2019.100182

117 Casey T, Wilson-Evered E. Predicting uptake of technology innovations in online family dispute resolution services: an application and extension of the UTAUT. Comput Human Behav 2012;28(06):2034-2045

118 Celik H. Customer online shopping anxiety within the Unified Theory of Acceptance and Use Technology (UTAUT) framework. Asia Pac J Mark Log 2016;28(02):278-307

119 Hsieh HL, Kuo YM, Wang SR, Chuang BK, Tsai CH. A study of personal health record user's behavioral model based on the PMT and UTAUT integrative perspective. Int J Environ Res Public Health 2016;14(01):E8

120 Chau P, Hu P. Examining a model of information technology acceptance by individual professionals: an exploratory study. J Manage Inf Syst 2002;18(04):191-229

121 Chau P, Hu P. Investigating healthcare professionals' decisions to accept telemedicine technology: an empirical test of competing theories. Inf Manage 2002;39(04):297-311

122 Hair J, Anderson R, Tatham R, Black J. Multivariate Data Analysis. 6th ed. Upper Saddle River, NJ: Prentice Hall; 2006

123 Gefen D, Straub D. The relative importance of perceived ease of use in IS adoption: a study of E-Commerce adoption. J Assoc Inf Syst 2000;1(01):1-30

124 Nunnally C, Bernstein I. Psychometric Theory (McGraw-Hill Series in Psychology), Vol 3. 2nd ed. New York, NY: McGrawHill; 1994

125 Duyck P, Pynoo B, Devolder P, Voet T, Adang L, Vercruysse J. User acceptance of a picture archiving and communication system. Applying the unified theory of acceptance and use of technology in a radiological setting. Methods Inf Med 2008;47(02):149-156

126 Hennington A, Janz B. Information systems and healthcare XVI: physician adoption of electronic medical records: applying the UTAUT model in a healthcare context. Comm Assoc Inform Syst 2007;19:60-80

127 Bandura A. Health promotion by social cognitive means. Health Educ Behav 2004;31(02):143-164

128 Berkman LF, Glass T, Brissette I, Seeman TE. From social integration to health: Durkheim in the new millennium. Soc Sci Med 2000;51(06):843-857

129 Rosenstock IM, Strecher VJ, Becker MH. Social learning theory and the health belief Model. Health Educ Q 1988;15(02): 175-183

130 Campbell K, Gordon L, Loeb M, Zhou L. The economic cost of publicly announced information security breaches: empirical evidence from the stock market. JComput Secur 2003;11(03): 431-448

131 Hsu C, Lin J. Acceptance of blog usage: the roles of technology acceptance, social influence and knowledge sharing motivation. Inf Manage 2008;45(01):65-74

132 Samhan B. Patients' resistance towards health information technology: a perspective of the dual factor model of IT 
usage. Paper presented at: Proceedings of the 50th Hawail International Conference on System Sciences; 2017, Hawaii United States

133 Cho H, Iribarren S, Schnall R. Technology-mediated interventions and quality of life for persons living with HIV/AIDS. a systematic review. Appl Clin Inform 2017;8 (02):348-368

134 Hoque MR, Bao Y, Sorwar G. Investigating factors influencing the adoption of e-Health in developing countries: a patient's perspective. Inform Health Soc Care 2017;42(01):1-17

135 Mbuagbaw L, Thabane L, Ongolo-Zogo P, et al. The Cameroon Mobile Phone SMS (CAMPS) trial: a randomized trial of text messaging versus usual care for adherence to antiretroviral therapy. PLoS One 2012;7(12):e46909

136 Faiola A, Holden RJ. Consumer health informatics: empowering healthy-living-seekers through mHealth. Prog Cardiovasc Dis 2017;59(05):479-486

137 Hamine S, Gerth-Guyette E, Faulx D, Green BB, Ginsburg AS. Impact of mHealth chronic disease management on treatment adherence and patient outcomes: a systematic review. JMed Internet Res 2015;17(02):e52

138 Price M, Yuen EK, Goetter EM, et al. mHealth: a mechanism to deliver more accessible, more effective mental health care. Clin Psychol Psychother 2014;21(05):427-436
139 Cho J. The impact of post-adoption beliefs on the continued use of health apps. Int J Med Inform 2016;87:75-83

140 Cho J, Quinlan MM, Park D, Noh GY. Determinants of adoption of smartphone health apps among college students. Am J Health Behav 2014;38(06):860-870

141 Alsharo M, Alnsour Y, Al-Aiad A. Exploring the change of attitude among healthcare professionals toward adopting a national health information system: the case of Jordan. Int J Bus Inf Syst 2019. Doi: 10.1504/IJBIS.2020.10019466

142 Aggelidis VP, Chatzoglou PD. Using a modified technology acceptance model in hospitals. Int J Med Inform 2009;78(02):115-126

143 Jian WS, Syed-Abdul S, Sood SP, et al. Factors influencing consumer adoption of USB-based Personal Health Records in Taiwan. BMC Health Serv Res 2012;12(01):277

144 Yang S. Understanding undergraduate students' adoption of mobile learning model: a perspective of the extended UTAUT2. J Converg Inf Technol 2013;8(10):969-979

145 Tavares J, Oliveira T. Electronic health record patient portal adoption by health care consumers: an acceptance model and survey. J Med Internet Res 2016;18(03):e49

146 Alsharo M, Alnsour Y, Alabdallah M. How habit affects continuous use: evidence from Jordan's national health information system. Inform Health Soc Care 2018. Doi: 10.1080/ 17538157.2018.1540423 